Sostenibilidad de pequeños productores en Tlaxcala, Puebla y Oaxaca, México

Tzatzil Isela Bustamante Lara, Benjamín Carrera Chávez y Rita Schwentesius Rindermann

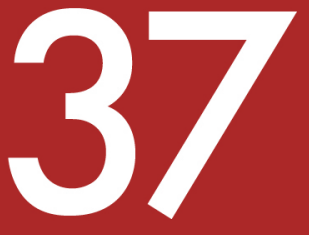

ENERO/ FEBRERO 2017

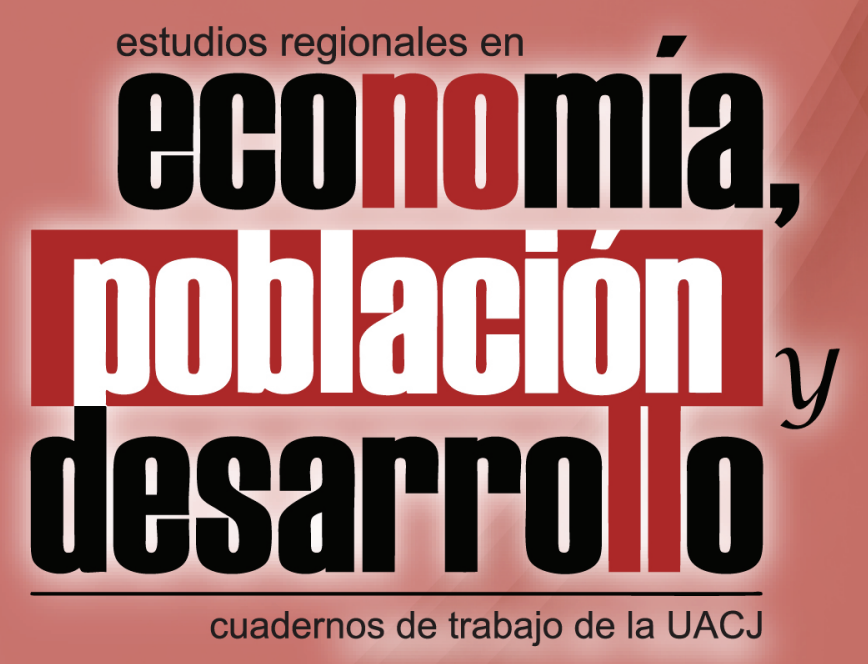




\title{
Sostenibilidad de pequeños productores en Tlaxcala, Puebla y Oaxaca, México
}

\author{
Tzatzil Isela Bustamante Lara, Benjamín Carrera Chávez \\ y Rita Schwentesius Rindermann
}




\title{
UNIVERSIDAD AUTÓNOMA DE CIUDAD JUÁREZ \\ Instituto de Ciencias Sociales y Administración
}

\author{
Cuerpo Académico de Estudios Regionales en \\ Economía, Población y Desarrollo
}

Lic. Ricardo Duarte Jáquez

Rector

M.C. David Ramírez Perea

Secretario General

Mtro. Juan Ignacio Camargo Nassar

Director del Instituto de Ciencias

Sociales y Administración

Mtro. Ramón Chavira Chavira

Director General de Difusión

Cultura y Divulgación Científica

Dr. Luis Enrique Gutiérrez Casas

Coordinador General de

Investigación y Posgrado

\section{Dr. Jaime Alberto Arellano Quiroga \\ Coordinador del Cuerpo Académico de \\ Estudios Regionales en Economía, Población y Desarrollo}

Director y editor

Dr. Luis Enrique Gutiérrez Casas

Comité editorial

Sección internacional

Dra. Sofía Boza Martínez (Universidad de Chile, Chile)

Dra. Olga Biosca Artiñano (Glasgow Caledonian

University, Reino Unido)

Dra. Ángeles Sánchez Díez (Universidad Autónoma de

Madrid, España)

Dr. Thomas Fullerton Mankin (University of Texas at

E1 Paso, Estados Unidos)

Dr. Adrián Rodríguez Miranda (Universidad de la

República, Uruguay)

Sección local

(Universidad Autónoma de Ciudad Juárez)

Dra. Myrna Limas Hernández

Dra. Ikuho Kochi

Dr. Raúl Alberto Ponce Rodríguez

Dr. Isaac Leobardo Sánchez Juárez

Dr. Héctor Alonso Barajas Bustillos

Diseño de cubierta Abigail Bautista
Estudios Regionales en Economía, Población

y Desarrollo. Cuadernos de Trabajo de la UACJ

ISSN 2007-3739

Número 37. Enero/ Febrero 2017

Sostenibilidad de pequeños productores en Tlaxcala, Puebla y Oaxaca, México

Tzatzil Isela Bustamante Lara, Benjamín Carrera Chávez

y Rita Schwentesius Rindermann

\section{Universidad Autónoma de Ciudad Juárez}

Estudios Regionales en Economía, Población y Desarrollo. Cuadernos de Trabajo de la UACJ

Año 7, No. 37 enero - febrero 2017, es una publicación bimestral editada por la Universidad Autónoma de Ciudad Juárez a través del Cuerpo Académico de Estudios Regionales en Economía, Población y Desarrollo del Instituto de Ciencias Sociales y Administración. Redacción: Avenida Universidad y H. Colegio Militar, Zona Chamizal s/n., C.P. 32300, Ciudad Juárez, Chihuahua, México. Teléfonos: (656) 688-38-00, ext. 3792. Correo electrónico: lgtz@uacj.mx.

Editor responsable: Luis Enrique Gutiérrez Casas. Reserva de derechos al uso exclusivo No. 04-2011-021713353900-102. ISSN 2007-3739, Impresa por Studio Los Dorados, calle Del Campanario, número 820-2, Santa Cecilia, C.P. 32350, Cd. Juárez, Chihuahua. Distribuidor: Subdirección de Gestión de Proyecto y Marketing Editorial. Ave. Plutarco Elías Calles 1210, Foviste Chamizal, C.P. 32310, Ciudad Juárez, Chihuahua. Este número se terminó de imprimir el 15 de octubre 2016 con un tiraje de 120 ejemplares.

Los ensayos publicados son responsabilidad exclusiva de sus autores. Se autoriza la reproducción total o parcial bajo condición de citar la fuente.

\section{Registrada en:}

Publicación afiliada a la Red Iberoamericana de Estudios del Desarrollo

Universidad Autónoma de Ciudad Juárez

Ave Plutarco Elías Calles 1210

Foviste Chamizal, C.P. 32310

Ciudad Juárez, Chihuahua, México

www.uacj.mx

(C) Universidad Autónoma de Ciudad Juárez 
Estudios Regionales en Economía, Población y Desarrollo. Cuadernos de Trabajo de la UACJ, Universidad Autónoma de Ciudad Juárez, número 37, enero-febrero de 2017, ISSN 2007-3739, pp. 3-33, México.

\title{
Sostenibilidad de pequeños productores en Tlaxcala, Puebla y Oaxaca, México
}

\author{
Tzatzil Isela Bustamante Lara*, Benjamín Carrera Chávez** \\ y Rita Schwentesius Rindermann***
}

Resumen

La agricultura orgánica es una de las actividades agrícolas con mayor crecimiento. En México, tanto el número de productores como de hectáreas dedicadas a la misma, aumentaron en los últimos años dando oportunidad a los pequeños productores de eliminar parte de la exclusión generada por la agricultura convencional y permitiéndoles ingresar al mercado. Sin embargo, es importante conocer la situación de estos productores desde diversas ópticas, por lo que en este trabajo se llevó a cabo la medición de su sostenibilidad económica, ecológica y socio-cultural con el fin de mostrar que su inclusión en tianguis y mercados orgánicos les permite sostenibilidad. Para esto, se seleccionaron tres mercados de la Red Mexicana de Tianguis y Mercados Orgánicos en los estados de Tlaxcala, Puebla y Oaxaca. Se aplicaron 30 encuestas y, los datos se agruparon en escalas de 0 a 4 indicando menor y mayor sostenibilidad respectivamente, (valores arriba de 2, implican sostenibilidad). Estos indicadores se ponderaron según su importancia. Los resultados muestran que los pequeños productores de estos tianguis son sostenibles económica y ecológicamente puesto que los valores arrojados por los indicadores fueron 2.62 y 2.5 respectivamente, sin embargo, en el criterio socio-cultural el resultado fue de 1.77 es decir, no sostenible. Por lo tanto se requiere llevar a cabo estrategias que mejoren el valor de estos indicadores a través de la promoción y difusión de productos orgánicos y el mercado local, concientización sobre las prácticas ecológicas y sus procesos y, la participación de más actores involucrados en esta práctica agrícola.

Palabras clave: Mercados orgánicos, alternativa, sostenibilidad, pequeños productores.

\begin{abstract}
Organic agriculture is one of the fastest growing agricultural activities. In Mexico, both the number of producers and hectares devoted to it increased in recent years, giving small producers an opportunity to eliminate part of the exclusion generated by conventional agriculture and allow them to get into the market. However, it is important to know the situation of these producers from various perspectives, so in this work the measurement of their economic, ecological and socio-cultural sustainability was carried out in order to show that their inclusion in tianguis and organic markets allows them to be sustainable. For this, three markets of the Red Mexicana de Tianguis y Mercados Organicos were selected in the states of Tlaxcala, Puebla and Oaxaca, 30 surveys were applied and the data were grouped in scales from 0 to 4 indicating lower and higher sustainability respectively, (values above 2, imply sustainability). These indicators were weighted according to their importance. The results show that the small producers of these farmer's markets are economically and ecologically sustainable since the values shown by the indicators were 2.62 and 2.5 respectively, however, in the socio-cultural criterion the result was 1.77 suggesting unsustainability. It is therefore necessary to establish strategies that improve the value of these indicators through the promotion and dissemination of organic products and the local market, creating conscience of ecological practices and processes and the participation of more actors involved in agricultural practices.
\end{abstract}

Key words: Organic markets, alternative, sustainability, small producers.

JEL Classification: Q01, Q12, Q56.

- Recibido en: Septiembre de 2016

- Aprobado en: Octubre de 2016

* Doctora en Ciencias en Economía Agrícola por la Universidad Autónoma Chapingo. Correo electrónico: tzatzi.bustamante@gmail.com.

** Profesor del Área de Economía del Departamento de Ciencias Sociales de la Universidad Autónoma de Ciudad Juárez. Correo electrónico: benjamín.carrera@uacj.mx.

*** Profesora del Centro de Investigaciones Interdisciplinarias para el Desarrollo Rural Integral (CIIDRI) de la Universidad Autónoma Chapingo. Correo electrónico: rschwent@prodigy.net.mx. 


\section{$\Rightarrow$ 1. Introducción.}

La agricultura es el conjunto de técnicas y conocimientos para cultivar la tierra. Actualmente, esta actividad se lleva a cabo mayormente de manera intensiva, generando lo que se conoce como agricultura moderna o convencional. En la cual, las grandes empresas tienen el poder de decidir qué y cuánto producir dictando entonces, el consumo de la población.

Éstas empresas también deciden cuáles serán los métodos de producción, implementado paquetes tecnológicos que incluyen desde la semilla mejorada, uso de fertilizantes químicos, control y manejo de plagas y enfermedades y en algunas ocasiones el uso de maquinaria lo cual, favorece a los grandes agricultores y ha dejado fuera a cerca de 1.4 mil millones de personas del medio rural, en su mayoría campesinos e indígenas con pequeñas granjas que generalmente cultivan en laderas y valles bajo métodos de producción tradicionales (Altieri, 2008:2).

La alta inversión en capital que este sistema requiere ha incrementado las diferencias entre campesinos pobres y ricos, la dependencia de predios agrícolas y el destino de la producción hacia las exportaciones, internacionalizando al modelo agrícola moderno e ignorando a casi 370 millones de pequeños productores que en su mayoría son ancianos, mujeres y niños y han quedado en extrema pobreza (Altieri, 2008:2).

La agricultura convencional incrementó los niveles de producción y la disponibilidad de alimentos por persona, uno de los factores que influyeron en estos aspectos fue la especialización en la producción la cual dirigió a la agricultura hacia el monocultivo, quien actualmente ocupa el 90\% de los 1.5 mil millones de hectáreas destinadas a la agricultura y que es altamente dependiente de insumos externos y energía, impactando negativamente en el medio ambiente, originando erosión, pérdida de fertilidad del suelo, agotamiento de las reservas de nutrientes, salinización, alcalinización y polución de los sistemas de agua, pérdida de agrobiodiversidad y recursos genéticos, eliminación de enemigos naturales, reaparición de plagas, resistencia genética a los plaguicidas y destrucción de los mecanismos de control naturales (SOCLA Y TWIN 2015:1; Altieri y Nicholls, 2000:116; Zayas et al., 2012: 436-440; Gómez, 2000:2).

En respuesta a estos hechos han surgido diversas iniciativas que, a través del diseño de agro ecosistemas diversificados y el uso de tecnologías de bajos insumos, demuestran la posibilidad de obtener un balance entre el medio ambiente y los rendimientos, facilitando la inversión de los pequeños productores y brindando tanto a éstos como a los consumidores, posibilidades fuera de la agricultura convencional.

Entre las alternativas más recurridas para esto, se encuentra la agricultura orgánica la cual, además de tener como objetivos a la conservación del medio ambiente y la regeneración de los recursos naturales trata de asegurar la autosuficiencia alimentaria y mejorar la equidad social y la 
viabilidad económica mediante la producción de alimentos sanos, promoviendo relaciones más justas y una buena calidad de vida para todos los involucrados (Altieri y Nicholls, 2000: 21-22; IFOAM, 2008). Lo cual a su vez, hace a este sistema de producción sostenible ecológica, económica y socio-culturalmente.

Actualmente, la agricultura orgánica es una de las actividades agrícolas con mayor crecimiento lo cual es una oportunidad para que los pequeños productores eliminen parte de la exclusión que les generó la globalización de la agricultura, permitiéndoles ingresar al mercado mundial.

Aunado a esto, la preocupación sobre el riesgo en la salud propiciado por las formas actuales de producción, procesamiento y comercialización de los alimentos, además del impacto de estos sistemas en el medio ambiente, han generado iniciativas para acceder a alimentos sanos y ecológicos (Escalona, 2009:227), logrando que instituciones de educación, culturales o municipales, apoyen el fomento en el consumo y comercialización de estos productos ya sea en tianguis y mercados orgánicos, tiendas especializadas, tiendas naturistas y cafeterías, que generalmente se ubican en las grandes ciudades del país y centros turísticos (Escalona, 2009:382).

Estas iniciativas han sido de gran importancia para el desarrollo de la agricultura orgánica y los pequeños productores. Por lo tanto, se debe aprovechar la etapa incipiente en la que se encuentra el mercado orgánico interno tanto para producción como para comercialización y, brindar a quienes llevan a cabo la agricultura orgánica, la oportunidad de ser autosuficientes y soberanos. En este sentido esta investigación ${ }^{1}$ se planteó responder a la interrogante sobre cuál es la situación actual en la sostenibilidad económica, ecológica y socio-cultural de los pequeños productores que dirigen su producción al mercado local mediante la comercialización en tianguis o mercados orgánicos integrados a la Red Mexicana de Tianguis y Mercados Orgánicos (REDAC), partiendo del hecho de que esta integración hace que los productores sean más sostenibles. Además de mostrar de manera descriptiva, la situación de la agricultura orgánica general en México y específica para los tianguis y mercados orgánicos.

Los trabajos que tratan sobre agricultura orgánica y sostenibilidad son diversos. Sin embargo, el abordaje más común respecto a estos temas está orientado hacia lo ambiental, sin considerar la situación a la cual se enfrentan diariamente los pequeños productores.

Una de las principales características de la sostenibilidad es su carácter multidimensional por lo que, es un tanto difícil llevar a cabo un trabajo que contemple la medición de éstos ámbitos en conjunto. En este orden de ideas, la principal aportación de la investigación será, llevar a cabo la

1 La información para este trabajo se obtuvo mayormente de la tesis doctoral del primer autor, denominada: Mercados orgánicos como medio de sostenibilidad para productores. 
medición de la sostenibilidad en sus criterios económicos, ecológicos y socio-culturales, además de la medición de un indicador de sostenibilidad a nivel general y la interpretación de los mismos.

\section{$\rightarrow$ 2. Marco conceptual.}

Este trabajo tiene como ejes centrales a la agricultura orgánica, la sostenibilidad y a los tianguis y mercados orgánicos de pequeños productores por lo tanto en esta sección se llevará a cabo una diferenciación sobre los sistemas de producción agrícola así como la definición sobre agricultura orgánica y sostenibilidad y la concepción de mercado y tianguis, así como de los sistemas de garantía sobre los cuales se contextualiza la investigación.

\subsection{Sistemas de producción agrícola.}

La agricultura es una actividad que comprende todo el conjunto de acciones humanas que transformen el medio ambiente natural, con el fin de hacerlo más apto para el crecimiento de la siembra. Es el arte de cultivar la tierra mediante diversos trabajos, como: el tratamiento del suelo, su explotación o el cultivo (Sáenz, 2009:3).

Debido a que los seres humanos desarrollaron la agricultura mediante su proceso evolutivo, ésta puede variar en muchas maneras y según diversos factores tales como los que se muestran en el Cuadro 1.

El conjunto de estos factores determinan el sistema bajo el cual la agricultura se llevará a cabo. Es interesante destacar los métodos y objetivos de producción ya que aquí es donde se crea divergencia y se conlleva hacia el debate. Tal es el caso de la agricultura convencional, la cual tiene como objetivo principal la producción masiva de alimentos con el mayor rendimiento y con principal fin para exportación; con respecto a los objetivos de la agricultura orgánica se encuentran el cuidado del impacto de la producción en el ambiente, mediante la conservación de los hábitats naturales y de la vida silvestre, y en el caso de la ganadería, atendiendo a las necesidades de nutrición, salud, desarrollo, comportamiento y bienestar de los animales, además de asegurar la sostenibilidad en la producción de alimentos y erradicar la pobreza, proporcionando seguridad y autosuficiencia alimentaria (Altieri y Nicholls 2000:21 y 29; Codex Alimentarius 2005:3 y; Zayas et al., 2012:444 y 445).

Entre los principales métodos de la producción convencional se encuentran, el mejoramiento genético, la tecnificación, mecanización y la utilización de agro tóxicos y pesticidas para el control de plagas, enfermedades y malezas mientras que en la producción agrícola orgánica esto se combate a través de rotación y variedad de cultivos, depredadores y abonos naturales y variedades resistentes, sustituyendo también agroquímicos por insumos orgánicos (Altieri y Nicholls 2000:21 y 29; Codex Alimentarius 2005:3 y; Zayas et al., 2012:444 y 445). 
Gráfica 1

\section{Sistemas de producción agrícola}

\begin{tabular}{|c|c|c|}
\hline \multirow{2}{*}{$\begin{array}{l}\text { 1) Factores ambientales (Según su } \\
\text { dependencia del agua }{ }^{2} \text { ) }\end{array}$} & De riego & $\begin{array}{l}\text { La disponibilidad de agua es a través de canales o } \\
\text { sistemas de riego artificial. }\end{array}$ \\
\hline & De temporal & Depende exclusivamente de las lluvias. \\
\hline \multirow{2}{*}{$\begin{array}{l}\text { 2) Magnitud de la producción y su } \\
\text { relación con el mercado }\end{array}$} & $\begin{array}{l}\text { Agricultura de } \\
\text { subsistencia }\end{array}$ & $\begin{array}{l}\text { Para el consumo del agricultor y su familia, emplea } \\
\text { técnicas tradicionales y depende de la lluvia. }\end{array}$ \\
\hline & Agricultura industrial & $\begin{array}{l}\text { Se realiza con maquinaria, semillas mejoradas y } \\
\text { fertilizantes. Utiliza riego artificial y obtiene } \\
\text { cosechas para la venta. }\end{array}$ \\
\hline \multirow{2}{*}{$\begin{array}{l}\text { 3) Según el máximo rendimiento o } \\
\text { la mínima utilización de otros } \\
\text { medios de producción }\end{array}$} & Agricultura intensiva & $\begin{array}{l}\text { Busca rendimientos grandes con la mínima } \\
\text { superficie. Conlleva al desgaste del sitio y } \\
\text { usualmente se practica en países industrializados. }\end{array}$ \\
\hline & Agricultura extensiva & $\begin{array}{l}\text { Depende del área de producción, causando menor } \\
\text { presión y relaciones ecológicas en la superficie. } \\
\text { Sus beneficios económicos son menores que en la } \\
\text { agricultura intensiva. }\end{array}$ \\
\hline \multirow{4}{*}{ 4) Métodos y objetivos } & $\begin{array}{l}\text { Agricultura } \\
\text { convencional, } \\
\text { industrial o moderna }\end{array}$ & $\begin{array}{l}\text { S. XX cambió el modelo agrícola mediante la } \\
\text { implementación de: paquetes tecnológicos } \\
\text { intensivos, mecanización, mejoramiento genético y } \\
\text { desarrollo de agroquímicos para el control de } \\
\text { plagas, enfermedades y malezas. }\end{array}$ \\
\hline & Agricultura tradicional & $\begin{array}{l}\text { Es todo tipo de agricultura antes de la revolución } \\
\text { verde. }\end{array}$ \\
\hline & Agricultura orgánica & $\begin{array}{l}\text { Surgió simultáneamente con algunos movimientos } \\
\text { contrarios a la revolución verde (1920). Es un } \\
\text { sistema producción que se basa en procesos } \\
\text { ecológicos, biodiversidad y ciclos adaptados, } \\
\text { combinando tradición, innovación y ciencia para } \\
\text { beneficiar el medio ambiente y a la sociedad". }\end{array}$ \\
\hline & $\begin{array}{l}\text { Agricultura natural, } \\
\text { integrada o mixta }\end{array}$ & $\begin{array}{l}\text { Es la combinación de la agricultura orgánica y la } \\
\text { convencional, con el plus de la conciencia } \\
\text { ambiental y la salud. }\end{array}$ \\
\hline
\end{tabular}

Fuente: Elaboración propia con base en información de Sáenz (2009:5-6), Altieri y Nicholls (2000:7),

Gómez (2000:2 y 10) y Rendón (2004:105).

\subsection{Agricultura orgánica.}

Debido a la variedad de escuelas y a los fines de las mismas respecto al movimiento orgánico, como menciona Boza (2012:5), es difícil consensuar una única definición para la agricultura orgánica. Sin embargo, para fines de esta investigación, se considera a la agricultura orgánica como

“un sistema de producción que mantiene y mejora la salud de los suelos, los ecosistemas y las personas. Se basa fundamentalmente en los procesos ecológicos, la biodiversidad y los ciclos adaptados a las condiciones locales, sin usar insumos que tengan efectos adversos. La agricultura orgánica combina tradición, innovación y ciencia para favorecer el medio

$2 \mathrm{http}: / /$ cuentame.inegi.org.mx/hipertexto/tipos_agua.htm. 
ambiente que compartimos y promover relaciones justas y una buena calidad de vida para todos los que participan en ella" (IFOAM, 2008).

Este sistema de producción tuvo sus inicios desde los años 20 a 60. En Europa surgió con Rudolf Steiner (1861-1925) quien la denominó, como cultivos biodinámicos considerando a éstos como un sistema de producción mixta que busca: equilibrio en la producción animal y vegetal; sistemas de reciclaje y; métodos de control de plagas y enfermedades de manera benigna. A lo cual, Hans Müller (1891-1988) agregó la fertilización del suelo mediante estiércoles frescos producidos por libre pastoreo y cuyos principios fueron establecidos por el investigador inglés Sir Albert Howard (1873-1947). En Gran Bretaña, el movimiento de la agricultura orgánica inició con Lady Eve Balfour (1899-1990), quién expuso que tanto la salud del suelo como la del hombre son inseparables. Jerome Irving Rodale (1898-1971) dio a este sistema de producción el término de agricultura regenerativa y la difundió en Estados Unidos a partir de 1940. Claude Aubert (1944), difundió la agricultura orgánica en Francia y es considerado uno de los principales promotores de la misma y, Mokiti Okada quien fue la base para el desarrollo de la agricultura natural en Japón durante 1985 (Gómez, 2000:10; Zayas et al., 2012:441 y 442).

Sus iniciativas se dieron debido a la preocupación por el impacto de los métodos de producción de alimentos sobre la salud humana, la cual fue creciendo después de la revolución verde, que intensificó el uso de plaguicidas y fertilizantes sintéticos. Esta fue la causa de que los países desarrollados llevaran a cabo este sistema de producción, además de su interés de apoyar a los pequeños agricultores en la adopción de prácticas agrícolas sustentables a fin de mejorar sus formas de vida y las condiciones agroecológicas en áreas rurales. Para el caso de los países en desarrollo, la agricultura orgánica se dio principalmente debido al potencial del comercio de sus productos (Källander y Rundgren, 2009:13).

Entonces, la agricultura orgánica es una estrategia de desarrollo que trata de cambiar algunas de las limitaciones encontradas en la producción convencional, más que una tecnología de producción, es una estrategia de desarrollo fundamentada no sólo en un mejor manejo del suelo y uso de insumos locales, sino también en un mayor valor agregado y una cadena de comercialización más justa (Soto, 2003:3).

Uno de los aspectos más importantes respecto a la parte ambiental de la agricultura orgánica, es la sustitución de los agroquímicos por insumos orgánicos tales como: preparados de composta liquida, polvos de composta nutricional, control biológico (fungís, bacterias y especies de predadores naturales) y algunos insumos comerciales hechos con ingredientes naturales de plantas (ajo, neem, ruda, epazote, orégano, etcétera) y aditivos minerales (calcio, sulfato de cobre), setos y trampas como feromonas y plástico (Gómez et al., 2005:468). 
Cabe destacar que la agricultura orgánica rescata las prácticas de producción tradicionales, lo cual no significa que descarte los avances tecnológicos siempre y cuando estos no sean contaminantes (Soto, 2003:5).

Respecto a lo social, la agricultura orgánica ofrece una alternativa para el desarrollo y fortalecimiento del sector rural, especialmente en áreas donde se presentan dificultades para implementar modelos tecnológicos convencionales, con alta incidencia de marginación o con presencia de grupos indígenas que figuran como los principales exponentes del modelo orgánico de producción (De la Cruz et al., 2012:531).

Durante su desarrollo, la agricultura orgánica ha tenido tres etapas, la primera de 1924 a 1970 donde el ambiente era hostil puesto que existían dificultades financieras para establecer el movimiento orgánico; de 1970 a 1980 se dio el crecimiento de los movimientos verdes y ecologistas y, se incrementó la demanda de productos orgánicos mediante el establecimiento de esquemas; de 1980 a la fecha, surgió la agricultura orgánica debido a los problemas toxicológicos, los daños a la salud humana, ambiental y animal y, este movimiento se dio finalmente tanto a nivel internacional como nacional (Zayas et al., 2012:442).

Aunado a la preocupación por la degradación ambiental y los problemas de salud derivados del manejo de los plaguicidas en todo el mundo, los agricultores han optado por convertirse a la agricultura orgánica debido al crecimiento del mercado y los esquemas de apoyo gubernamental, lo cual ha hecho económicamente atractiva a la producción orgánica.

Para algunos grupos de productores particularmente en América Latina y Filipinas, el acceso y el control de los recursos de producción como: semillas, tecnología, endeudamiento y la dependencia de los campesinos respecto a los insumos externos, son poderosas fuerzas impulsoras. En estos casos, la conversión tiene una fuerte dimensión social y una agenda política (Källander y Rundgren, 2009:19). Por lo tanto, el futuro de la agricultura orgánica será determinado por relaciones de poder y no existe razón para que los agricultores y el público en general, si son suficientemente empoderados, no puedan influir en la dirección acorde con los objetivos de la sostenibilidad (Altieri, 2009:18).

Actualmente, se han logrado diversas acciones estratégicas para el desarrollo del sistema agrícola orgánico. Entre las más importantes están: la organización del sector, las alianzas, el ingreso de estos productos en supermercados y eventos internacionales $\mathrm{y}$, la participación de los agricultores en las prácticas y mercados orgánicos. Además, los escándalos y desarrollos negativos de la agricultura convencional han contribuido a concientizar a los consumidores y aumentar la participación de los productores orgánicos al mercado. Un ejemplo de esto fue el brote de Encefalopatía Espongiforme Bovina (EEB) y las campañas de Reino Unido e Italia respecto a: "El verdadero costo de la agricultura" (Källander y Rundgren, 2009:19). 
Sin embargo, aún existen obstáculos que superar, los principales son la falta de oferta y escasa variedad de productos, además de la debilidad en el desarrollo del mercado doméstico lo que conlleva al desinterés de los actores a lo largo de la cadena de provisión, inhibiendo la demanda del consumidor y el progreso de productos en la industria (Källander y Rundgren, 2009:21).

\subsection{Sostenibilidad.}

La sostenibilidad, desarrollo sostenible o crecimiento sustentable, indica que cada generación dejará a la generación siguiente agua, aire, suelo tan puro e impoluto como cuando vino a la tierra. Involucrando solamente la conservación de recursos de manera general, sin determinar qué es lo que debe ser conservado (Martinet, 2009:183). Por lo tanto, esta definición es vaga y está fundamentalmente equivocada ya que hace que la sostenibilidad sea una obligación no factible. Entonces, lo que la sostenibilidad pretende es dejar la posibilidad a las futuras generaciones para que estas alcancen sus objetivos. Es decir, se debe tomar en cuenta el vínculo entre sostenibilidad y bienestar intergeneracional (Fleurbaey, 2015:34), abarcando diferentes puntos de interés y garantizando que al satisfacer las necesidades presentes no se comprometerán las necesidades de generaciones futuras (Méndez y Sáez, 2007:6).

Es importante considerar los bienes sustitutivos respecto a la producción ya que el principio de la sostenibilidad no consiste en dejar a las generaciones futuras una cosa en específico sino, la capacidad de darles la oportunidad de crear bienestar (Solow, 1991: 182). Además, la satisfacción de las necesidades presentes, sin comprometer la habilidad de las generaciones futuras para satisfacer sus propias necesidades, implica dos conceptos: 1) la necesidad, la cual se refiere a tener lo esencial para las personas más pobres en el mundo dando a estos prioridad absoluta y, 2) la idea de las limitaciones impuesta por el estado de la tecnología y, la organización social respecto a la capacidad del medio ambiente para satisfacer las necesidades presentes y futuras (World Comission on Environment and Development, 1987).

Entonces, la definición más indicada es que la sostenibilidad es la obligación de comportarnos de tal manera que dejemos en el futuro, la opción o la capacidad de estar tan bien como nosotros lo estamos (Solow, 1991: 179-181).

La sostenibilidad tiene la característica de ser multidisciplinaria, por lo tanto su definición varía, según el criterio del cual se trate:

En el sentido económico, la sostenibilidad "es un conjunto de patrones económicos a través de los cuales el bienestar intergeneracional no disminuye" (Arrow et al., 2010: 2).

En el contexto ambiental, se considera como la habilidad de un agro ecosistema para mantener la producción a través del tiempo, en presencia de repetidas restricciones ecológicas y presiones socioeconómicas (Altieri y Nichols, 2000:24). 
Respecto a lo social, también se denomina como desarrollo humano y, se logra a través de la inversión en educación, salud, nutrición y la participación de la comunidad en las sociedades. Se refiere a que una persona tenga al menos lo más básico para cubrir sus necesidades, haciendo hincapié en la equidad y el empoderamiento a largo plazo. Su objetivo principal es la reducción de la pobreza (Roy y Goll, 2014:851).

En cuanto a lo cultural, determina el comportamiento de los miembros de una sociedad mediante la provisión de una lógica general o dominante, considerándola como el valor y normas que actúan como institución informal y afectan la interacción humana (Roy y Goll, 2014:850).

Dentro del ámbito rural, la sostenibilidad considera diversos principios que van acorde con la productividad en relación a las condiciones del medio ambiente y el nivel de rentabilidad económica aceptable para las familias rurales y; la tecnología, la cual no debe degradar los recursos naturales ni la salud humana. Mejorando el nivel de vida de los productores y la población en general de manera inmediata (Rendón, 2004:49).

\subsection{Mercado.}

Este trabajo de investigación se centra en la comercialización mediante mercados o tianguis, orgánicos, los cuales representan la conexión entre consumidores y productores. En este caso, la concepción de mercado/tianguis es de manera espacial, es decir, como un lugar donde se lleva a cabo el intercambio de mercancías procedentes de la agricultura orgánica. Por lo tanto, se hace referencia a un espacio público, de acceso abierto, donde los productores ofrecen alimentos provenientes de sus propias unidades productivas, bajo las normas de producción orgánica, generando alternativas sobre la producción y el consumo locales y, tomando en cuenta el valor del origen de los productos destinados a satisfacer las necesidades de los consumidores (Escalona, 2009).

\subsection{Sistemas de Garantía.}

Estos sistemas surgieron con el propósito de garantizar que un determinado producto es producido bajo diversos criterios y normas de producción previamente establecidos.

Debido a que la agricultura orgánica ha crecido de manera dinámica en los últimos años hasta el punto de lograr convertirse en un sector reconocido a nivel mundial, se ha generado de manera paralela la proliferación de regulaciones y exigencias normativas para la producción y certificación de productos orgánicos (CIAO e IICA, 2010:1).

Para este caso, bajo el sistema de producción orgánica el sistema de garantía es la certificación orgánica en la cual se incluye la no utilización de plaguicidas y fertilizantes químicos, el respeto de los ritmos de producción, formación y crecimiento de la naturaleza, la utilización de preparados biodinámicos, rotación de cultivos, y producción combinada con tradición e innovación. Con esto 
se ha logrado construir confianza entre comprador y productor, así como protección al productor orgánico de la competencia desleal (Jovchelevich, 2013:1-2; Van Elzakker y Eyhorn, 2010:85).

Entre otro de los principales objetivos de la certificación orgánica está el mejoramiento en las ventas de los productos orgánicos (De la Cruz et al., 2012:524).

Este tipo de certificación, puede llevarse a cabo mediante terceros, es decir, a través de una agencia o mediante un Sistema Participativo de Garantía (SPG) y, la elección entre estas dependerá principalmente del tipo de mercado que el productor pretenda cubrir.

Generalmente el SPG se utiliza cuando se comercializa la producción de un gran número de pequeños productores, utilizando una certificación grupal basada en un Sistema de Control Interno (SCI) que debe seguir ciertas normas. Si el producto está destinado para la exportación dichas normas también cambiarán según el país al que se pretenda ingresar el producto (Van Elzakker y Eyhorn, 2010:1 y 85).

En las dos siguientes secciones se mostrará el surgimiento y desarrollo de los sistemas de certificación de la producción orgánica, con el fin de identificar algunos procesos y normas que los productores deben seguir para garantizar que sus productos son orgánicos.

\subsubsection{Certificación Orgánica por Agencia.}

Se considera de tercera parte, cuando la entidad que la ejecuta es completamente independiente, sin ningún interés o relación con el proceso productivo o la comercialización (González, 2010:31). La certificación orgánica por agencia se lleva a cabo mediante las etapas que se muestran en la Figura 1.

Las primeras agencias certificadoras surgieron de asociaciones y cooperativas vinculadas tanto con productores como consumidores y fueron Demeter Internacional (1991); Nature et Progres; Naturland; Soil Association. En los últimos 20 años estas han incrementado en número debido principalmente a los países que destinan su producción orgánica a la exportación (IFOAM preámbulo III, 2013).

Sin embargo, los altos costos para la certificación orgánica por agencia así como los numerosos requisitos que se deben cumplir frenan la incorporación de mayores áreas de producción al sistema orgánico, por lo tanto la oportunidad de los pequeños productores de integrarse al mercado (De la Cruz et al., 2012:520). Debido a esto, América Latina desarrolló alternativas para cumplir con los requisitos de certificación necesarios mediante la participación de diversos actores, creando los SPG. 
Figura 1

\section{Esquema de la certificación orgánica por agencia}

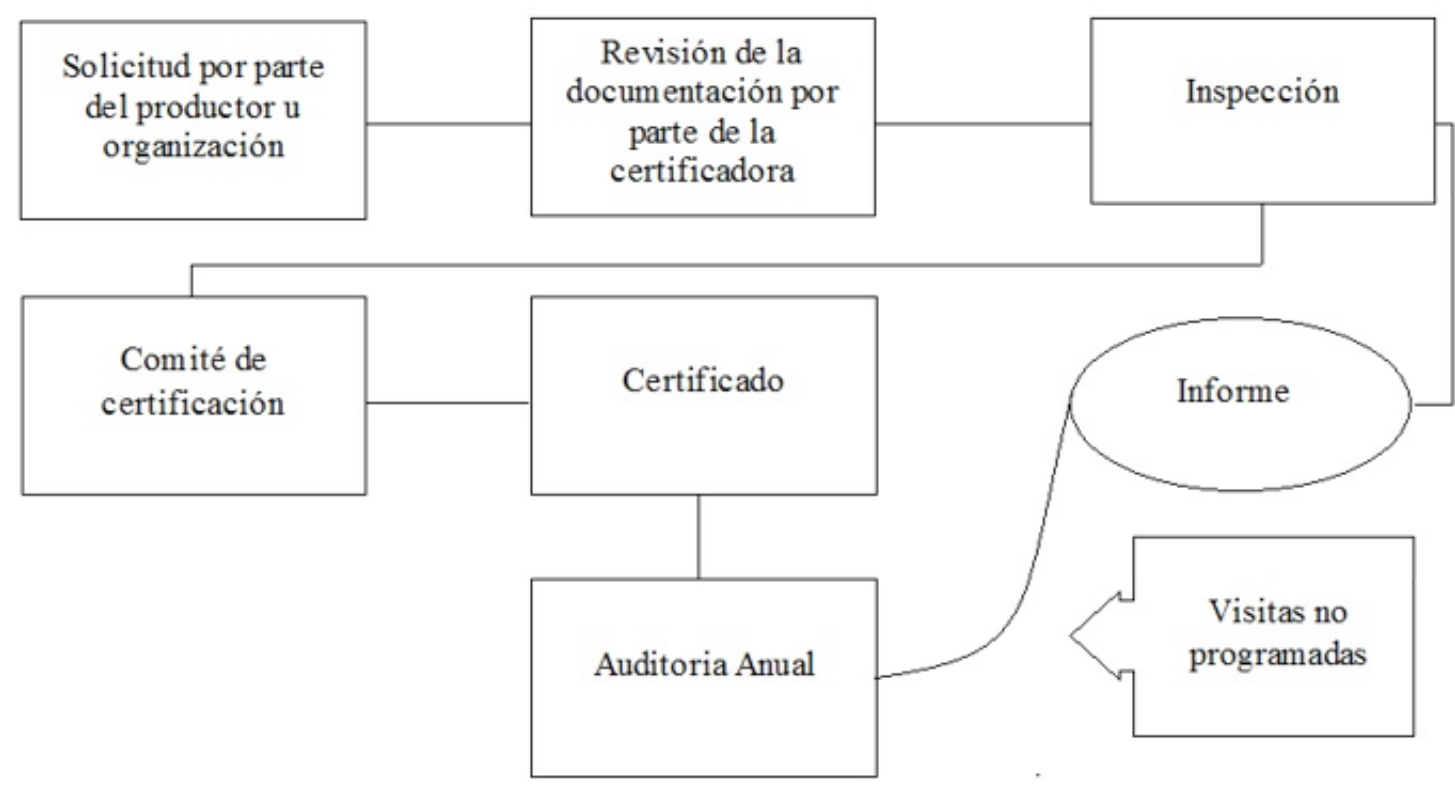

Fuente: Elaboración propia con base en comunicación personal.

\subsubsection{Sistema Participativo de Garantía.}

E1 SPG “es un proceso colectivo entre productores, consumidores y otros actores, que garantiza la calidad orgánica y sana de productos locales, generados a pequeña escala, basados en relaciones de confianza y, que promueve los compromisos de salud, ecología, equidad y certidumbre ambiental" (Schwentesius et al., 2013:25).

La certificación orgánica mediante el SPG es una herramienta que brinda confianza cuando se sustenta en principios y reglamentos definidos, aceptados y vigentes junto con la participación de todos los actores involucrados en el sector orgánico, ya sean públicos o privados (Williamson y Kingston, 2010:2). Además los SPG deben cumplir con cuatro principios básicos tal como se muestra en el Cuadro 2.

En cuanto a los reglamentos que aseguran que la producción sea orgánica, la organización Soil Association del Reino Unido, fue la primera en publicar los estándares que aseguran este tipo de producción; posterior a esto, la Federación Internacional de Movimientos de Agricultura Orgánica (IFOAM) publicó sus primeros estándares en 1980 y a partir de 1990 los gobiernos iniciaron la tarea de definir las reglas en cuanto al procesamiento, producción y comercialización de los productos orgánicos y en algunos casos hasta se dieron la tarea de agregar aspectos relativos con la certificación y acreditación de la producción (De la Cruz et al., 2012:519). 
Cuadro 2

\section{Principios del Sistema de Certificación Orgánica Participativa}

\begin{tabular}{|l|l|}
\hline \multicolumn{2}{|c|}{ Principios de la Certificación Orgánica Participativa } \\
\hline Participación & $\begin{array}{l}\text { Se da cuando todos los actores que participan en el movimiento orgánico (productores, } \\
\text { consumidores, distribuidores y comercializadores entre otros), están comprometidos con el } \\
\text { diseño inicial y el funcionamiento de la Certificación Participativa (CP) es decir, todos los } \\
\text { actores toman decisiones estratégicas para el funcionamiento de la misma. }\end{array}$ \\
\hline $\begin{array}{l}\text { Visión } \\
\text { compartida }\end{array}$ & $\begin{array}{l}\text { Surge cuando los actores apoyan de manera colectiva los principios centrales de la CP } \\
\text { (objetivos de la producción orgánica, objetivos relacionados a las normas, justicia social, } \\
\text { comercio justo, cuidado del medio ambiente, autonomía de las comunidades locales, } \\
\text { diferencias culturales, etcétera). }\end{array}$ \\
\hline Transparencia & $\begin{array}{l}\text { Se logra cuando todos los actores están informados sobre el funcionamiento exacto del sistema } \\
\text { de garantia incluyendo: reglamentos, normas y la toma de decisiones. Es decir, los interesados } \\
\text { deben tener un entendimiento básico de cómo funciona el sistema o al menos saber cómo } \\
\text { obtener dicha información. Para lograr la transparencia se debe tener un sistema claramente } \\
\text { definido y documentado, acceso público a la documentación e información sobre la CP ya sea } \\
\text { mediante la web, noticias públicas o reuniones con los interesados. }\end{array}$ \\
\hline Confianza & $\begin{array}{l}\text { Se basa en el compromiso individual de cada productor con la protección del medio ambiente } \\
\text { y la salud de los consumidores a través, de la producción orgánica. Los mecanismos para } \\
\text { expresar dicha credibilidad se basan en: un documento de declaración y proclamación de la } \\
\text { conciencia individual y colectiva. Puede expresarse a través de una declaración escrita u oral. }\end{array}$ \\
\hline Horizontalidad & $\begin{array}{l}\text { No debe haber jerarquías sino, una estructura general y democrática a través de la } \\
\text { responsabilidad colectiva. }\end{array}$ \\
\hline
\end{tabular}

Fuente: Elaboración propia con base en información de May (2008: 4-8).

\section{Metodología.}

Tal como se planeta en los objetivos, esta investigación busca llevar a cabo una medición de la sostenibilidad de los pequeños productores que se integran a los tianguis y mercados orgánicos de la REDAC, tomando en cuenta los criterios económicos, ecológicos y socio-culturales. Además, de hacer una descripción sobre la situación de la agricultura orgánica en México y exponer conjuntamente la importancia y funcionamiento de los tianguis y mercados orgánicos en el país. Esto debido a que aunque la agricultura orgánica sea un sector en crecimiento, la falta de información limita su estudio.

\subsection{Análisis descriptivo.}

Para cumplir con los objetivos, se llevó a cabo la búsqueda de información de fuentes electrónicas, además de la aplicación de 30 encuestas a productores en tres de los 21 tianguis y mercados que integran a la REDAC para obtener fuentes de información directas.

3 La Certificación participativa es el equivalente al SPG, sin embargo su nombre no se puede modificar debido a cuestiones normativas en México. 
Los tianguis que se seleccionaron se muestran en el Cuadro 3, y fueron elegidos debido a la cercanía entre ellos, además de la similitud en las condiciones de los productores, la oferta de productos, la organización interna y accesibilidad de productores y coordinadores para facilitar la información.

Cuadro 3

Tianguis y mercados orgánicos encuestados, número de productores y fecha de visita

\begin{tabular}{|c|c|c|c|}
\hline \multicolumn{1}{|c|}{ Tianguis o Mercado } & Productores & $\begin{array}{c}\text { \% de } \\
\text { encuestas }\end{array}$ & \multicolumn{1}{c|}{ Fecha de visita } \\
\hline Mercado Alternativo Tlaxcala & 6 & 20 & 8 de agosto de 2014 \\
\hline Tianguis Alternativo de Puebla & 10 & 33 & 8 de noviembre de 2014 \\
\hline $\begin{array}{l}\text { Tianguis Alternativo Pochote } \\
\text { Xochimilco }\end{array}$ & 14 & 47 & 28 de noviembre de 2015 \\
\hline Total & 30 & 100 & - \\
\hline
\end{tabular}

Fuente: Elaboración propia con base en las encuestas aplicadas de agosto 2014 a noviembre 2015.

\subsection{Indicadores de sostenibilidad.}

Respecto al objetivo de la medición de la sostenibilidad, éste se llevó a cabo en tres fases: 1) la planeación de la investigación, donde se consideró el método y enfoque sobre el cual se dirigiría el estudio, el alcance y diseño de la investigación y, el diseño y prueba de los instrumentos de recolección; 2) el levantamiento y captura de la información que incluye, la selección de la población objetivo, la aplicación del instrumento de recolección y el diseño de la base de datos y captura de la información y, 3) el cálculo de los indicadores de sostenibilidad.

Existen muchos indicadores e índices que intentan medir la sostenibilidad en las diversas categorías de la misma. Sin embargo, para la medición de la sostenibilidad de los productores de los tianguis y mercados que forman parte de la REDAC, se utilizaron los indicadores de sostenibilidad: 1) económica, 2) ecológica y 3) socio-cultural. Una vez calculados estos indicadores se puede medir un Indicador de Sostenibilidad General.

Para llevar esto a cabo fue necesario, estandarizar la información mediante escalas de 0 a 4 indicando mayor y menor sostenibilidad respectivamente. Posteriormente, los indicadores se ponderaron multiplicando el valor de la escala por un coeficiente según la importancia relativa de cada variable respecto a la sostenibilidad, éste es un paso que puede hacerse por consenso, por medio de la consulta de expertos o según la opinión de los agricultores (Sarandón et al., 2008:21). Para el caso de este trabajo la ponderación se llevó a cabo por el grado de importancia de los indicadores según la literatura y a consideración de los autores. Los indicadores a calcular, son:

\subsubsection{Indicador de Sostenibilidad Económica (ISE).}

El cual indica que para que haya sostenibilidad económica se deben reducir costos y aumentar la eficiencia y viabilidad económica promoviendo un sistema agrícola diverso y flexible (Altieri y 
Nichols, 2000:23).

Por lo tanto, la hipótesis es que un sistema será económicamente sostenible si brinda autosuficiencia alimentaria, si genera al grupo familiar un ingreso anual y si disminuye el riesgo en el tiempo (Sarandón et al., 2008:21). Este indicador está compuesto por:

a) El Indicador de Autosuficiencia Alimentaria (IAA), que incluye los subindicadores de: diversificación en la producción en la cual, un sistema es más sostenible si su producción es diversificada y alcanza a cubrir el nivel nutricional de la familia, por lo tanto, según el resultado de las encuestas se hizo una clasificación respecto a la cantidad de productos que los productores tienen en sus parcelas y que pueden servir de autoconsumo. El otro subindicador es el de superficie de producción de autoconsumo donde, el sistema es sostenible si la superficie destinada para la producción de alimentos para el consumo es adecuada con el número de integrantes del grupo familiar.

b) Indicador de Ingreso Semanal Neto por Grupo (ISNG), este indicador muestra que el sistema es sostenible si puede satisfacer las necesidades económicas del grupo familiar (Sarandón et al., 2008:22). Para el caso de este trabajo se refiere a si solamente con la venta de la producción orgánica se pueden satisfacer las necesidades del productor y su familia.

c) El Indicador de Riesgo Económico (IRE), que incluye la diversificación para la venta. Se refiere a si el productor puede comercializar más de un producto, suponiendo que si el productor sufriera alguna perdida o daño en la producción, tendría la capacidad de compensar esta pérdida con algún otro producto. Para esto también se llevaron a cabo rangos respecto al número de productos ofrecidos por el productor en los tianguis y mercados orgánicos encuestados; el número de canales de comercialización donde, la diversificación en estos canales disminuye el riesgo económico, y; la dependencia de insumos externos. Para esto, se considera que el sistema es más sostenible cuando su dependencia de insumos externos es menor. Entonces, en este caso se consideró el porcentaje en que los pequeños productores obtienen sus insumos y preparan sus abonos o fertilizantes orgánicos.

Debido a la ponderación que se dio a los indicadores anteriores, la ecuación algebraica para medir el Indicador de Sostenibilidad Económica, es:

$$
I S E=\frac{2(I A A)+I I S N G+I R E}{4}
$$


El indicador de autosuficiencia alimentaria y el subindicador de dependencia de insumos externos fueron ponderados con el doble de peso debido a que se consideran más importantes que el resto de las variables. Por lo tanto, sustituyendo las variables se obtiene la siguiente ecuación:

$$
I S E=\frac{2\left(\frac{D P+S P A}{2}\right)+I I N S G+\frac{D V+C C+2 D I E}{4}}{4}
$$

\section{Donde:}

ISE=Indicador de Sostenibilidad Económica

$D P=$ Diversificación en la Producción

$S P A=$ Superficie de Producción para Autoconsumo

IINSG=Indicador del Ingreso Neto Semanal por Grupo

$D V=$ Diversificación para la Venta

$C C=$ Canales de Comercialización

DIE=Dependencia de Insumos Externos

\subsubsection{Indicador de Sostenibilidad Ecológica (ISEC).}

La sostenibilidad ecológica a largo plazo debe reducir el uso de energía y recursos; la pérdida de nutrientes; estimular la producción local de cultivos adaptados al conjunto natural y socioeconómico y; sustentar la producción mediante la minimización en la degradación del suelo (Altieri y Nichols, 2000:23).

Entonces, los principios agroecológicos para el manejo sostenible de los agros ecosistemas contemplan:

a) La diversificación vegetal y animal a nivel de especies o genética en tiempo y en espacio.

b) El reciclaje de nutrientes y materia orgánica, mediante la optimización de la disponibilidad y balances del flujo de los mismos.

c) La reducción en la pérdida de nutrientes mediante la contención efectiva de la lixiviación, escurrimiento, erosión y mejora del reciclado de los mismos.

d) La provisión de condiciones edáficas óptimas para el crecimiento de cultivos manejando materia orgánica y estimulando la biología del suelo.

e) La minimización de pérdidas de agua y suelo manteniendo la cobertura de este último, controlando la erosión y manejando el microclima. 
g) La explotación de sinergias que emergen de interacciones planta-planta, plantas-animal y animal-animal. Indicando además, que la investigación y el desarrollo agrícola deben operar sobre la base de un enfoque desde abajo, comenzando con lo que está ahí es decir, la gente el lugar, sus necesidades y aspiraciones, sus conocimientos de agricultura y recursos naturales autóctonos (Altieri y Nichols, 2000:92).

Por lo tanto, la hipótesis sobre la sostenibilidad ecológica indica que, el sistema será ecológicamente sostenible si es capaz de conservar o mejorar la base de los recursos de la producción, evitando o disminuyendo el impacto sobre los recursos extra prediales, considerando tanto los recursos propios como externos (Sarandón et al., 2008:21). Para llevar a cabo la medición de la sostenibilidad ecológica se utilizan tres indicadores con sus respectivos subindicadores, que son:

a) El Indicador de Manejo del Suelo (IMS), que incluye el subindicador de riesgo de salinización y la conservación de la estructura, los cuales no se consideraron por falta de información. Sin embargo, este indicador también incluye al subindicador de la conservación de materia orgánica, el cual, contempla a la diversidad de la materia orgánica según las prácticas en las fincas tomando en cuenta todas las actividades que mejoren la fertilidad del suelo (abonos verdes, bocachi, ceniza, composta, estiércol, hojarasca, humus de lombriz, microorganismos aplicados al suelo y rastrojo).

b) Indicador de Manejo de Diversidad Vegetal (IMDV), que incluye la conservación de la diversidad espacial y temporal, los cuales se refieren respectivamente a la diversidad de cultivos, dónde el valor de las escalas se representa mediante: 0 que indica una situación de monocultivo, 1 poca diversificación de cultivos; 2 diversidad media de cultivos; 3 alta diversificación de cultivos y; 4 diversificación total de cultivos con asociaciones entre ellos y vegetación natural (Sarandón et al., 2008:23) y, a la rotación de cultivos ya que ésta aumenta la diversidad en el tiempo, haciendo al sistema más productivo. La escala de este indicador es: 0 no hay rotación de cultivos; 1 realiza rotaciones eventualmente; 2 realiza rotaciones no planificadas (sino de acuerdo a las observaciones del productor); 3 lleva a cabo rotaciones planificadas según los requerimientos del cultivo y la incorporación de materia orgánica y; 4 hace rotaciones anuales considerando e incorporando el descanso del suelo e incorporando leguminosas o abonos verdes (Sarandón y Dellepiane, 2008:72; Sarandón et al., 2008:22).

c) Indicador del Régimen de Tenencia de la Tierra (IRTT) que indica, que el sistema es más sostenible cuando hay un sentimiento de propiedad puesto que la responsabilidad y preocupación por la conservación de los recursos es mayor (Sarandón y Dellepiane, 2008:72). La escala utilizada en éste caso, va de 0 a 4 indicando menor y mayor sostenibilidad respectivamente. 
Los tres indicadores que conforman al ISEC se ponderaron de igual forma, por lo tanto, la ecuación algebraica para medir la sostenibilidad ecológica, es:

$$
I S E C=\frac{I M S+I M D V+I R T T}{3}
$$

Todos los indicadores se ponderaron de igual manera, obteniendo la siguiente ecuación:

$$
I S E C=\frac{C M O+\left(\frac{C D E+C D T}{2}\right)+R T T}{3}
$$

Donde:

ISEC $=$ Indicador de Sostenibilidad Ecológica.

$C M O=$ Conservación de la Materia Orgánica.

$C D E=$ Conservación de la Diversidad Espacial .

$C D T=$ Conservación de la Diversidad Temporal.

IRTT=Indicador del Régimen de Tenencia de la Tierra.

\subsubsection{Indicador de Sostenibilidad Socio-Cultural (ISSC).}

Para que la agricultura sea sostenible, esta debe ser cultural y socialmente aceptada, esto hace referencia a la preservación del capital social que pone en funcionamiento al capital natural. Cabe destacar que este hecho se vuelve más importante cuando se trata de pequeños productores o de campesinos de bajos recursos ya que, sus conocimientos, valores, cultura, condiciones de vida y su grado de aceptación, son los factores que impulsan la toma de sus decisiones (Sarandón, 2002:402-403).

Por lo tanto, la hipótesis sobre la sostenibilidad socio-cultural indica que el sistema será sostenible si logra mantener o mejorar el capital social, lo cual implica que haya personas que pongan en funcionamiento el capital natural o ecológico, es decir, mano de obra. Además, se debe mejorar también la satisfacción del productor, su calidad de vida, nivel de dependencia e integración social y sus niveles de conciencia y conocimiento ecológicos (Sarandón et al., 2008:21).

Por lo tanto, para medir la sostenibilidad socio-cultural se requiere del cálculo de cuatro indicadores con sus respectivos subindicadores, que son:

a) El Indicador de Satisfacción de las Necesidades Básicas (ISNB) que, incluye los subinicadores de acceso a la educación donde se considera si los productores tuvieron o tienen acceso a la información o cursos de capacitación (Sarandón et al., 2008: 23). En éste trabajo hace una modificación y se toma en cuenta el grado de escolaridad máximo al que llegaron los productores obteniendo y asignando valores de 0 a la educación básica, 1 a la media, 2 a la media superior, 3 a la educación superior y 4 para quienes estudiaron algún posgrado; respecto al subindicador de vivienda se clasifica en escalas de sostenibilidad

Economía, Población y Desarrollo. Cuadernos de Trabajo de la UACJ, núm. 37, ene-feb 2017 
que van de 0 a 4 según el tipo de obra y el material del cual se construyó la vivienda. Debido a la información obtenida en las encuestas se hizo una modificación donde se considera el tamaño del hogar respecto al número de habitaciones, asignando las escalas de 0 para una habitación, 1 a dos habitaciones 2 a tres habitaciones, 3 a cuatro habitaciones y 4 a más de 4 habitaciones.

b) El indicador de Aceptación del Sistema Productivo (IASP) el cual, determina que la satisfacción del productor está directamente relacionada con su aceptación al sistema productivo. A mayor satisfacción, menor riesgo de abandonar la modalidad de producción en el tiempo. Este indicador puede hacer escalas de sostenibilidad basadas en el grado de satisfacción del productor, donde 0 indica que esta desilusionado con la vida que lleva o no la haría más, 1 está poco satisfecho, 2 no está del todo satisfecho pero es lo único que sabe hacer, 3 está contento pero antes le iba mejor y 4, está muy contento con lo que hace. Este indicador también puede incluir las razones por las cuales el productor lleva a cabo esta actividad (Sarandón et al., 2008: 23; Sarandón y Dellepiane, 2008:72). Para el caso de este trabajo el cuestionario que se aplicó a los productores incluye una pregunta sobre las razones para llevar a cabo la producción orgánica, donde la escala fue de 0 para las razones comerciales, 1 debido al conocimiento del tema, 2 para autoconsumo, 3 para reducir los riesgos en la salud y, 4 para el cuidado del medio ambiente.

c) El Indicador de Integración Social (IIS), este evalúa la relación del productor con otros miembros de la comunidad y se clasifica en cuatro escalas donde el 0 indica nula relación, 1, baja relación (pertenece a 1 ó 2 grupos u organizaciones), 2 media (pertenece a 3 ó 4 grupos u organizaciones), 3 alta (5 a 6 organizaciones o grupos) y 4 muy alta relación (más de 6 grupos u organizaciones) (Sarandón et al., 2008: 23). Para el caso de este trabajo, la escala es la misma, sin embargo, los datos se obtuvieron de dos preguntas que indicaban si el productor pertenecía a algún grupo organizado de productores (cooperativa, ejido, sociedad de productores, unión de ejidos, etcétera), en conjunto con la pregunta de si pertenece o vende sus productos en otro lugar.

d) El Indicador del Conocimiento y Conciencia Ecológica (ICCE) este indicador es fundamental para la toma de decisiones adecuadas para el cuidado y conservación del medio ambiente y los recursos naturales. Considera una escala de 0 a 4 donde: 1 no presenta conocimiento ecológico ni concibe las consecuencias que pueden tener algunas prácticas, 2 tiene solamente una visión parcializada de la ecología y la sensación de que algunas prácticas pueden dañar el medio ambiente, 3 sus conocimientos se reducen a la finca con el no uso de agroquímicos más prácticas conservacionistas por lo tanto, su conocimiento 
es con la práctica cotidiana y, 4 concibe la ecología desde un punto de vista amplio más allá de la finca y conoce sus fundamentos (Sarandón et al., 2008: 23). Para el caso de este trabajo, las escalas se hicieron según la asesoría técnica que los productores reciben por lo tanto la escala de medición de la sostenibilidad es 0 para ninguna fuente de asesoría, 1 para una fuente de asesoría técnica, respectivamente, hasta asignar un valor de 4 para más de tres fuentes de asesoramiento.

Respecto a los indicadores que conforman al ISSC, se consideraron más importantes a la satisfacción de necesidades básicas y al grado de adaptabilidad del sistema productivo, por lo tanto, la ponderación se hizo como se muestra en la siguiente ecuación:

$$
I S S C=\frac{2\left(\frac{(I N B)}{3}\right)+2(I A S P)+I I S+I C C E}{6}
$$

Sustituyendo los subindicadores, se tiene:

$$
I S S C=\frac{2\left(\frac{V+2 A E}{3}\right)+2(I A S P)+I I S+I C C E}{6}
$$

\section{Donde:}

ISSC =Indicador Socio-Cultural.

$V=$ Vivienda.

AE=Acceso a la Educación.

IASP=Indicador de Aceptación del Sistema Productivo.

IIS=Indicador de Integración Social.

ICCE=Indicador de Conocimiento y Conciencia Ecológica.

\subsubsection{Indicador de Sostenibilidad General (ISG).}

Entonces, de conformidad con lo anterior, para que la agricultura sea sostenible debe cumplir con principios como: a) la tierra debe ser suficientemente productiva; b) ecológicamente adecuada (conservando la base de recursos naturales y preservando la integridad del ambiente a nivel local regional y global); c) económicamente viable y d) cultural y socialmente aceptable. De esta manera, la sostenibilidad abarca y evalúa aspectos económicos, ecológicos, socio-culturales (Sarandón, 2002:402).

Y, para llevar a cabo la medición de la sostenibilidad a nivel general es necesario calcular el ISG el cual valora las tres áreas u objetivos anteriores por igual, por lo tanto la ecuación algebraica para calcularlo, es:

$$
I S G=\frac{I S E+I S E C+I S S C}{3}
$$


El valor de este indicador debe estar entre 2 y 4 de lo contrario los productores no serán sostenibles. Sin embargo, el indicador puede ser sostenible en lo general y no sostenible en alguno de los criterios individuales.

\section{$\Rightarrow$ 4.Resultados y discusión.}

Actualmente, México es uno de los principales productores orgánicos de América Latina (Flores, 2015:228).Por lo tanto, es importante fomentar la participación de los productores en tianguis o mercados orgánicos ya que con esto, se logrará conectar a la población del campo y la ciudad, dando promoción al mercado regional y el consumo directo, y creando conciencia ecológica y social mediante la oferta de alimentos sanos, de alta calidad, en volúmenes adecuados y con sistemas de control y capacitación que resguarden los lineamientos de producción y garanticen efectivamente el esquema de producción es orgánico (Gómez y Gómez, 2004:17).

\subsection{Situación de la agricultura orgánica en México.}

La agricultura orgánica es una actividad con gran potencial en la generación de empleos y divisas puesto que requiere de un 30\% más de mano de obra que la producción convencional. En 2007/08 generó 172,293 empleos directos y 394,149 millones de dólares en divisas (Gómez et al., 2010). Para 2013, México reportó un total de 501,364 hectáreas (ha) destinadas para la producción orgánica, logrando incrementar su TMCA a 9.28\% durante el periodo de 1997 a 2013. En este mismo periodo, la agricultura orgánica pasó de representar el $0.05 \%$ de la superficie total cultivable a 2.3\%, con una TMCA de 6.06\% (Gómez et al., 2010; Lernoud y Willer, 2015:36 y 41; Schwentesius, 2015). Además, México es el país de Latinoamérica con el mayor número de productores orgánicos, con un total de 169,703 de los cuales son en su mayoría pequeños productores con menos de tres hectáreas (Schwentesius et al., 2013: 25).

Dentro del ámbito internacional de lo orgánico, México se ubica como país productor-exportador y no como consumidor ya que, aproximadamente el $85 \%$ de la producción orgánica es enviada al extranjero (Schwentesius et al., 2013). Por ello, el mercado interno se encuentra en una etapa incipiente ya que sólo se consume 15\% de la producción orgánica total (Schwentesius et al., 2013).

Respecto al uso de la tierra, los cultivos con mayor superficie agrícola orgánica son: el café con 242,603 ha que representan el $48.38 \%$ de la superficie orgánica total; seguidos de frutas tropicales y semitropicales (principalmente mango y aguacate), con 57,266 ha (11.43\%); vegetales con 46,573 ha (9.28\%); granos de cacao 19,382 ha (3.86\%) y cítricos con 11,917 ha (2.37\%), los cuales en conjunto, representan el $75.34 \%$ de la superficie agrícola orgánica total (Schwentesius, 2015). Chiapas y Oaxaca son los líderes en la producción orgánica, seguidos de Michoacán, Querétaro y Guerrero quienes tienen dos tercios del total de la producción agrícola orgánica en México (Gómez 
et al., 2010:22 -25).

Respecto al consumo per cápita de productos orgánicos en 2013, México gasta 0.1 euros anuales, en lo referente a las ventas minoristas, el país reportó 14 millones de euros (Lernoud y Willer, 2015:65: Willer y Lernoud, 2015: 279)

En cuanto a la certificación, México cuenta con alrededor de 3,000 hectáreas certificadas mediante CP (Kirchner, 2015:136). Durante 2013, 18\% de los integrantes de los diferentes tianguis y mercados orgánicos en México, contaban con un certificado de agencia. Entre los principales productos certificados se encuentran: los lácteos y cárnicos (res y cerdo), productos transformados como sazonadores, miel de agave y mezcal. Mientras que el $60 \%$ de los productos cuentan con CP por parte de algún tianguis o mercado (Schwentesius et al., 2013:25).

Después de años de trabajo intenso por parte del movimiento orgánico mexicano se crearon diversos marcos regulatorios como: la Ley de Productos Orgánicos en 2006, el Reglamento de la Producción Orgánica en 2010 y los Lineamientos de la Producción Orgánica en 2013 (Jarquín et al., 2013:4; Flores, 2015:228).

\subsubsection{REDAC.}

La Red Mexicana de Tianguis y Mercados Orgánicos, fue creada en el año 2004 e inició con 4 mercados que son: el Círculo de Producción y Consumo Responsable, El Tianguis Orgánico Chapingo, el Tianguis Agroecológico de Xalapa y El Mercado Alternativo Tlaxcala. Fue constituida legalmente en 2008 con el objetivo de acceder a recursos financieros para su desarrollo. Es un grupo de la sociedad civil, integrada por tianguis y mercados orgánicos locales y regionales de pequeños o medianos productores, consumidores y promotores. De 2004 a 2010 la REDAC contó con el apoyo financiero de la Organizacion No Gubernamental Falls Brook Centre de Canadá, esto permitió cubrir gastos de dos a tres reuniones al año, pagando a dos representantes por mercado o tianguis, los gastos de alimentación, alojamiento y traslado, además se cubrieron gastos de promoción y difusión. Durante 2010 y 2011 se consiguió un financiamiento por parte de la Secretaría de Agricultura, Ganadería, Desarrollo Rural, Pesca y Alimentación (SAGARPA) para apoyar la CP; con esto, se organizaron talleres de capacitación respecto a la producción y certificación así como materiales de divulgación. Cabe destacar que, en la actualidad la red no recibe contribuciones económicas directas por parte de los integrantes a los mercados y tianguis (Schwentesius et al., 2013:31 y 32).

Debido a que los tianguis y mercados orgánicos abarcan desde Baja California hasta Chiapas, en 2010 la REDAC se dividió en tres regiones: centro-norte, golfo y sur. Su origen se dio debido a la creciente cantidad de tianguis y mercados orgánicos a lo largo de la república Mexicana en especial en el centro y sur del país. El surgimiento de estos mercados fue con iniciativa de académicos, consumidores y ONGs, quienes invitaron a productores a venderles sus productos una vez por semana (Schwentesius et al., 2013:21, 22 y 27). 
Entre los principales objetivos de la red según su acta constitutiva, se incluye:

a) Promover la reconversión de productos convencionales y naturales a orgánicos y, el desarrollo y adaptación de ecotecnologías alternativas disminuyendo la dependencia de elementos externos al sistema.

b) Asesorar en materia de CP.

c) Vincular y promocionar los diferentes tianguis y mercados orgánicos en México fortaleciendo el comercio local y justo.

d) Realizar estudios de diagnóstico de tipo económico, tecnológico y social.

e) Participar en eventos académicos, científicos y de divulgación a nivel nacional e internacional y fomentar actividades de formación a través de cursos, talleres, conferencias y otros medios.

f) Celebrar los contratos y ejecutar los actos que sean relativos y conexos con los fines sociales y adquirir los bienes muebles e inmuebles para los establecimientos y servicios de la Asociación, además de participar activamente en el diseño y formulación de políticas públicas relacionadas con la producción local de productos orgánicos.

La REDAC, también tiene como meta específica el mejoramiento de la tierra a través de la agricultura orgánica y los participantes de los mercados que forman parte de la red, tomando en cuenta el concepto de sostenibilidad en el cual incluyen los factores ecológicos, económicos, socio-culturales y de salud (Schwentesius et al., 2013:22-23).

Actualmente, la red cuenta con un total de 21 tianguis y mercados orgánicos en 15 estados a lo largo de la República mexicana como se muestra en el Cuadro 4. 
Cuadro 4

Tianguis y mercados orgánicos que integran la REDAC

\begin{tabular}{|l|l|l|}
\hline \multicolumn{1}{|c|}{ Estado } & \multicolumn{1}{c|}{ Lugar } & \multicolumn{1}{c|}{ Nombre del tianguis/mercado } \\
\hline Baja California & San José del Cabo & Mercado Orgánico San José del Cabo \\
\hline Chiapas & Tapachula & Tianguis de Productos Naturales y Orgánicos- El Huacalero \\
\hline Distrito Federal & Distrito Federal & Tianguis Alternativo Bosque de Agua \\
\hline \multirow{2}{*}{ Estado de México } & Chapingo & Tianguis Orgánico Chapingo \\
\cline { 2 - 3 } & Metepec & Tianguis Orgánico Bosque de Agua \\
\hline Guanajuato & San Miguel de Allende & Tianguis Orgánico, Natural y Artesanal de San Miguel de Allende \\
\hline Guerrero & Cocoyuca & Tianguis Campesino de Cocoyuca de Benítez y Atoyac \\
\hline Jalisco & Guadalajara & Círculo de Producción y Consumo Responsable \\
\hline Morelos & Tepoztlán & Mercado Orgánico de Tepoztlán Ameyalli Tlacualli \\
\hline \multirow{3}{*}{ Oaxaca } & Ixtlán de Juárez & Tianguis Orgánico Yuu Vaan de la Sierra de Juárez \\
\cline { 2 - 3 } & Oaxaca & Tianguis Alternativo Pochote Xochimilco \\
\cline { 2 - 3 } & Oaxaca & El Pochote Productos Orgánicos \\
\hline Puebla & Puebla & Tianguis Alternativo de Puebla \\
\hline Querétaro & Querétaro & Tianguis Orgánico Bosque de Agua \\
\hline \multirow{2}{*}{ Quintana Roo } & & Universidad del Caribe \\
\cline { 2 - 3 } & Playa del Carmen & La Miscelanea Orgánica \\
\hline San Luis Potosí & San Luis Potosí & Mercado Orgánico Macuilli Teotzin \\
\hline \multirow{2}{*}{ Tlaxcala } & Tlaxcala & Mercado Alternativo de Tlaxcala \\
\cline { 2 - 3 } & Apizaco & Mercado Alternativo Tlaxcala Apizaco \\
\hline \multirow{2}{*}{ Veracruz } & Coatepec & Mercado Bioregional Coatl \\
\cline { 2 - 3 } & Xalapa & Mercado Agroecológico de Xalapa \\
\hline
\end{tabular}

Fuente: Elaboración propia con base en información obtenida de fuentes directas.

\subsubsection{Descripción general de los tianguis y mercados orgánicos de Oaxaca, Puebla y Tlaxcala.}

En México, los primeros tianguis y/o mercados orgánicos surgieron de manera independiente y en diferentes contextos, pero siempre en áreas urbanas. El inicio de estos tianguis y mercados se dio en Guadalajara en 1998, la primera propuesta fue establecida como un punto de venta llamado Ecotienda, la cual surgió por la inquietud de diversos ciudadanos por dar seguimiento a las prácticas aprendidas en los talleres de educación ambiental que promovía el Colectivo ecologista de Jalisco en la década de los 80. Posteriormente, se vincularon diversos productores constituyendo el Círculo de Producción y Consumo Responsable, transformando a la Ecotienda en un espacio semanal para llevar a cabo el intercambio entre el campo y la ciudad, promoviendo alternativas de producción orgánica local, de comercio justo y consumo responsable, en donde las actividades didácticas, de promoción, difusión y vinculación son fundamentales (García, 2015:138 y 139).

En 2001, se creó la Red de Consumidores de Productos Orgánicos en Chapingo con iniciativa de estudiantes, académicos y consumidores. Para 2003, esta idea se transformó con la participación de grupos académicos de la Universidad Autónoma Chapingo, consumidores, organizaciones 
de la sociedad civil, estudiantes y productores, en el Tianguis Orgánico Chapingo cuya intención era llevar a cabo un intercambio material, cultural y de vinculación donde la idea principal fue la venta directa (García, 2015:140).

La tercera iniciativa se dio por el interés de consumidores y productores preocupados por el medio ambiente, la sanidad y la seguridad alimentaria quienes organizaron tres ferias orgánicas contactando a los productores del municipio de Teocelo (Veracruz). De ahí partió la idea de abrir un mercado orgánico permanente y, para 2003 se creó el Tianguis Agroecológico de Xalapa. La Universidad Veracruzana apoyó este proyecto y aportó personal académico para su coordinación.

La idea principal del de este tianguis fue la promoción de productores de áreas rurales cercanas y la venta directa (García, 2015:142).

Para 2003, surgió el Tianguis Orgánico el Pochote como protesta a la instalación de un McDonald's en el centro histórico de Oaxaca. Este proyecto se llevó a cabo por iniciativa de profesores, artistas y productores invitados (Nelson et al., 2007:7).

Otra de las iniciativas de tianguis y mercados orgánicos en México es El Mercado Alternativo Tlaxcala, las reuniones para su creación comenzaron en 2003, sin embargo, el mercado inicio actividades en 2005. Su finalidad fue la promoción de la cultura del consumo responsable y la producción agroecológica en sus aspectos sociales, económicos, ambientales y culturales. El desarrollo de este mercado se dio con la participación de Ana Elena Caballero (coordinadora del proyecto), organizaciones como: el Proyecto de Desarrollo Integral Vicente Guerrero A.C., El Centro Campesino para el Desarrollo Sustentable A.C., Casa de Promoción Social Presentación de Tlaxcala y el Herbario de Tlaxcala. Entre otros actores están: La Dra. Rita Schwentesius, el Dr. Manuel Ángel Gómez Cruz, la Mtra. Laura Gómez Tovar quienes brindaron asesoría en el proceso, El Sr. Santiago Martini, la Sra. Ofelia Cova Juárez y el Dr. Jürgens (con apoyo en principios cooperativos, promoción y procesos productivos respectivamente) (García, 2015:144).

Entre las características principales de los mercados, está la promoción de una mejor alimentación mediante productos orgánicos y la protección del medio ambiente. Sin embargo, todos los tianguis y mercados son entidades independientes y cada uno cuenta con sus propias características (REDAC, 2013; Schwentesius et al., 2013:22-23).

En cuanto a los productos que los tianguis y mercados ofrecen en general, tienen que ser acorde a la canasta básica y, los más comunes son: el café y sus derivados, productos de abeja tales como miel, propóleos, jalea real y derivados, hortalizas y verduras (como acelga, apio, betabel, brócoli, calabaza, cebolla, cebollines, chayote, chícharos, diversos tipos de lechuga, nopales, jitomate, zanahoria, etcétera), frutas, legumbres, hierbas y especies, además de alimentos de origen animal como huevo, carne, productos lácteos, productos procesados y comida preparada.

En cuanto a la identificación del productor, el promedio de edad de los productores de los 
tianguis y mercados orgánicos de Oaxaca, Puebla y Tlaxcala es de 42 años (oscilando entre los 82 y 23 años). La participación por género se divide en 63\% hombres y 37\% mujeres.

El $57 \%$ de los encuestados indicaron respecto a su estado civil que son solteros y $43 \%$ casados, sin embargo el 50\% cuenta con dependientes económicos, para lo cual el promedio es de tres hijos.

Respecto a la situación de pertenencia a grupos étnicos, el 33\% de los encuestados, integran grupos entre los que están, Chinanteco, Mixteco, Náhuatl, y Zapoteco. El 30\% de los encuestados indicaron haber modificado su lugar de residencia y, entre los principales motivos que manifestaron fueron, mejorar la calidad de vida y por las oportunidades laborales.

En lo referente a cuestiones del hogar, el 83\% de los encuestados cuenta con hogar propio, $13 \%$ paga renta y solamente una persona se encuentra en situación de préstamo. El promedio de renta mensual del hogar es de 2,875 pesos (con el pago menor de 1,500 y mayor de 4,500 pesos) y, el promedio de dormitorios por hogar es de 2 a 3 (menor 1, mayor 6), habitados por 3 ó 4 personas (oscilando entre 1 y 8 ).

En lo relativo a la escolaridad, el 14\% de los productores encuestados respondieron que cuentan con escolaridad a nivel básico; el 7\% educación media; el 5\% educación media superior; $60 \%$ educación superior con carreras como: agronomía, contaduría, sociología, antropología, enfermería, entre otras. El 10\% cuenta con posgrado y $4 \%$ con escuela técnica.

Esta situación implica que en general, los productores son jóvenes y con grados de escolaridad que les permiten adoptar nuevos métodos de producción y aprovechamiento.

Los productores mencionan que decidieron iniciar con la producción orgánica porque consideran que es un buen negocio y sabían del tema, además que les ayuda a cubrir su propio consumo, cuida el medio ambiente y reduce los riesgos en la salud que ha generado el consumo de productos convencionales, los cuales están fertilizados y abonados con químicos y agro tóxicos.

Entre los factores que consideraron de mayor importancia al momento de iniciar con la producción orgánica, se encontraba la facilidad de llevar a cabo la producción, el precio al cual se podía vender el producto, que fuera un producto que tuviera fines de autoconsumo, que el costo de producción fuera bajo o pudiera ser compensado con el precio de venta y que la producción no afectara la salud del medio ambiente.

E1 87\% de los productores, indicó que no ha solicitado ningún tipo de financiamiento para llevar a cabo su producción, sin embargo el 13\% mencionaron haber solicitado apoyo a instituciones y programas como: Gobierno del Estado, Secretaría de Economía. Sin embargo, no se les otorgó el financiamiento.

Con base en las encuestas aplicadas, el $77 \%$ de los productores mencionaron que produce en terreno propio, el 7\% rentan el terreno y el 7\% son acopiadores. Quienes rentan sus parcelas, 
pagan en promedio mensual una cantidad de 650 pesos (mínimo 200, máximo 900 pesos).

Respecto a la producción, el área de producción promedio es de 5.34 ha (para cuatro personas esto no aplica puesto que son acopiadores o producen en la cocina de su casa).

Los productores trabajan en sus parcelas un promedio de 35 horas ( 2 productores no respondieron y los otros 4 son acopiadores). El 74\% de los encuestados respondió que cuenta con apoyo en el trabajo de la parcela. El promedio de empleados es de 3 a 4 personas, solamente una persona indicó que tienen más de 10 empleados. De este total, el 47\% mencionó que las personas que le ayudan son familiares y el promedio semanal que estas personas trabajan en la parcela es de 25 horas. Respecto al salario que estos ayudantes perciben semanalmente es, para el $47 \%$ de 0 a 500 pesos; para el $17 \%$ de 501 a 1,000 pesos y para el 4\% de 1,001 a 1,500, de 1,501 a 2,000 y más de 2,501 pesos respectivamente.

Según sus métodos de producción, 77\% de los encuestados mencionaron que obtienen las materias primas que utilizan de su misma producción, el 15\% las consiguen con sus compañeros o en otros tianguis o mercados orgánicos y, el 8\% directamente con el productor (generalmente estas personas producen alimentos procesados como el pan), en este caso los datos se hicieron en base a la respuesta de 26 productores puesto que cuatro no son solamente comercializadores o acopiadores.

El 88\%, de los productores aplican en sus parcelas algún tipo de fertilizante o abono orgánico, entre los que se encuentran los fertilizantes foliares, humus de lombriz, microorganismos, compostas, violes, caldos minerales, rastrojo, cal, lixiviados etcétera. Estos abonos se aplican en promedio tres veces al año y el costo promedio aproximado de su aplicación es de 2,015 pesos anuales (el promedio se obtuvo de 20 de los 30 productores que aplican fertilizantes o abonos ya que de estos, 5 mencionaron que estas aplicaciones no les generan costos extras puesto que las obtienen de su producción o el desecho de su consumo, cuatro son acopiadores y una persona no respondió).

Respecto a las enfermedades más comunes, estas son: Antracnosis (Colletotichum Acuatum), Bacteria Pseudomona (Pseudomonas aeruginosa), Cenicilla (Oidiopsis taurica), Hongos (Colletotichum Acuatum y Chauistle), Roya (Puccinia sorghi) y Tizón (Phytophthora infestans) y, las plagas más comunes son: Ácaros Acari (varroa), hormigas (Formica Spp), alfilerillo o gusano del alambre (Agriotes spp), lombriz de tierra (Lumbricus terrestres), broca (Hypothenemus hampei), mosquita blanca o de la col (Pieris brassicae, leptophobia aripa), caracol (Helix aspersa), oruga (Pieris rapae) entre otras.

Tanto para prever y combatir plagas y/o enfermedades utilizan la rotación y diversidad de cultivos, malezas, acolchado, barreras, aclareo, poda, resiembra, platos de melaza, antiácidos, cambios de temperatura o preparados de ingredientes tales como cebolla, chile, jabón, epazote, chicalote, ajo, timo, eucalipto. El promedio anual en el que realizan estas actividades es de aproximadamente ocho veces. Respecto al costo anual derivado del control de plagas y enfermedades 
para el 57\% de 0 a 200 pesos; para el 7\% de 201 a 400 pesos y para el 17\% de 401 a 600 , para el $10 \%$ de 601 a 800 pesos y de 1,001 pesos en adelante para el 10\% restante.

En referencia a la comercialización, los productores indicaron que para poder formar parte de alguno de los tianguis o mercados orgánicos integrados a la REDAC tuvieron que seguir diversos procesos entre los que están: 1) cumplir con los lineamientos y normas para la producción orgánica; 2) llenar una solicitud o cuestionario; 3) recibir una visita y; 4) recibir un dictamen de rechazo o aceptación al tianguis. Algunos integrantes mencionaron que iniciaron en el tianguis por invitación o incluso fueron fundadores. Otro de los requisitos para integrarse o mantenerse en los tianguis y mercados de la red es que los productores cuenten con la CP y se les asigne una categoría según el método bajo el cual producen, situación que es similar en la mayoría de los tianguis como se muestra en el Cuadro 5.

Cuadro 5

\section{Comité de Certificación Participativa y Clasificación a los productores en los tianguis encuestados}

\begin{tabular}{|l|l|l|}
\hline \multicolumn{1}{|c|}{$\begin{array}{c}\text { Tianguis/ } \\
\text { Mercado }\end{array}$} & \multicolumn{1}{|c|}{ Certificación participativa } & \multicolumn{1}{c|}{ Clasificación } \\
\hline $\begin{array}{l}\text { Mercado Alternativo } \\
\text { Tlaxcala }\end{array}$ & $\begin{array}{l}\text { Cuenta con un Comité de Certificación } \\
\text { Participativa (cCP) desde 2003 } \\
\text { Integrantes del CCP: presidente, secretario y } \\
\text { tesorero, } \\
\text { Funcionamiento: calendario de visitas } \\
\text { Certificación: anual }\end{array}$ & No se especificó \\
\hline $\begin{array}{l}\text { Tianguis Alternativo } \\
\text { de Puebla }\end{array}$ & $\begin{array}{l}\text { Tiene un CCP integrado por productores y } \\
\text { consumidores }\end{array}$ & $\begin{array}{l}\text { Orgánicos, en transición, naturales, } \\
\text { socialmente responsables, } \\
\text { biodegradables y tradicionales }\end{array}$ \\
\hline $\begin{array}{l}\text { Tianguis Orgánico el } \\
\text { Pochote Xochimilco }\end{array}$ & $\begin{array}{l}\text { Cuenta con un cCP, integrado por: presidente, } \\
\text { auxiliar y 2 observadores. } \\
\text { Funcionamiento: reunión quincenal, visita es } \\
\text { sorpresa los días jueves. }\end{array}$ & $\begin{array}{l}\text { Algunos ponen en sus mesas sus } \\
\text { dictámenes de Certificación } \\
\text { Participativa o de agencia }\end{array}$ \\
\hline
\end{tabular}

Fuente: Elaboración propia con base a las encuestas aplicadas de agosto 2014 a noviembre 2015.

Cabe destacar que la certificación participativa no tiene ningún costo, sin embargo, algunos productores apoyan a los integrantes del CCP con gastos de transporte o alimentación.

Respecto a la perspectiva de los productores, se les preguntó qué puntos consideran que se deben tratar para mejorar su producción. En orden de importancia, indicaron que: debe haber un aumento en la asesoría técnica y capacitación sobre los métodos de producción; incremento de los canales de comercialización e; implemento de apoyos económicos, institucionales (para insumos y tecnificación como insecticidas, abonos y semillas de origen orgánico) y, para acreditaciones y certificaciones.

En cuanto a su situación económica, los productores indican que podrían mejorarla si pudieran tener más asesoría técnica o capacitaciones que aumenten su producción. Además, consideran que implementar un sello que garantice que lo que ellos producen es en efecto orgánico podría 
incrementar sus ventas. Algunos productores mencionaron que el apoyo económico también podría incrementar su producción y les generaría mayores beneficios. Para otros productores lo más importante es mejorar la organización interna del mercado en que se encuentran para así tener canales de comercialización fuertes y poder dar mayor difusión a lo que se produce bajo el sistema orgánico.

\subsection{Medición de la sostenibilidad.}

Respecto a la escala de medición de sostenibilidad, para cada indicador se asignaron valores de 0 a 4, donde cero hace referencia a la menor sostenibilidad y 4 mayor sostenibilidad, haciendo más sencillo llevar a cabo la agrupación y comparación de los resultados. Para el cálculo de los indicadores se consideró la moda en la respuesta de los encuestados. Cabe destacar que el indicador es sostenible cuando el resultado se encuentra entre 2 y 4 . Respecto al Indicador de sostenibilidad económica, los resultados obtenidos se muestran en el Cuadro 6.

Cuadro 6

Resultados más altos de las escalas de sostenibilidad por indicador y subindicador de la Sostenibilidad Económica ${ }^{4}$

\begin{tabular}{|c|c|c|c|c|c|c|}
\hline \multicolumn{2}{|c|}{ Indicadores/ subindicadores } & $\begin{array}{c}\text { Valor obtenido } \\
\text { en la escala de } \\
\text { sostenibilidad }\end{array}$ & MAT $^{\mathbf{5}}$ & TAP $^{\mathbf{6}}$ & TAEPX $^{7}$ & $\begin{array}{c}\text { Total } \\
\text { productores }^{2}\end{array}$ \\
\hline \multirow{3}{*}{ IAA } & Diversificación de la Producción (DP) & $\mathbf{4}$ & 2 & 3 & 5 & 10 de 30 \\
\cline { 2 - 7 } & Superficie de Producción de Autoconsumo & $\mathbf{3}$ & 2 & 2 & 2 & 6 de $26^{*}$ \\
\hline \multirow{2}{*}{ IISNG } & Ingreso Semanal Neto por Grupo (ISNG) & $\mathbf{0}$ & 5 & 6 & 3 & 14 de $23 * *$ \\
\hline \multirow{3}{*}{ IRE } & Diversificación para la Venta (DV) & $\mathbf{4}$ & 5 & 4 & 5 & 14 de 30 \\
\cline { 2 - 7 } & Canales de Comercialización (CC) & $\mathbf{2}$ & 0 & 4 & 6 & 10 de 30 \\
\cline { 2 - 7 } & Dependencia de Insumos Externos (DIE) & $\mathbf{4}$ & 5 & 7 & 12 & 24 de 30 \\
\hline
\end{tabular}

Fuente: Elaboración propia con base a las encuestas aplicadas de agosto 2014 a noviembre 2015.

* Para cuatro no aplica porque son comercializadores.

** Siete personas no contestaron.

Desarrollando la ecuación del Indicador de Sostenibilidad Económica, en cada uno de sus componentes, se tiene:

$$
I S E=\frac{2((D P+S P A) / 2)+I I N S G+(D V+C C+2 D I E) / 4}{4}
$$

4 La Diversificación de la producción incluye más de 9 productos para autoconsumo; la Superficie de Producción de Autoconsumo/habitantes por hogar es $\leq 0.1$ ha; el Ingreso Semanal Neto por Grupo es $<2,001$ pesos; la Diversificación para la Venta es de más de 6 productos; El número de vías de comercialización es de tres y; la Dependencia de Insumos Externos es de 0 a $20 \%$.

Mercado Alternativo Tlaxcala.

Tianguis Alternativo de Puebla.

Tianguis Alternativo el Pochote Xochimilco. 
Con base en los resultados obtenidos en las encuestas y sustituyendo los valores, en la ecuación, se tiene:

$$
I S E=\frac{2((4+3) / 2)+0+(4+2+2(4)) / 4}{4}
$$

Entonces, el ISE tiene un valor de 2.62, indicando que los pequeños productores son sostenibles económicamente.

El único valor que resultó no sostenible fue en lo referente al ingreso semanal neto, donde los productores mencionaron ganar de 0 a 500 pesos semanalmente.

Para el Indicador de Sostenibilidad Ecológica, la escala de medición de la sostenibilidad fue nuevamente de 0 a 4 indicando la menor sostenibilidad y la mayor sostenibilidad respectivamente. La escala se considera sostenible cuando se ubica entre 2 y 4 y no sostenible de 0 a 1 . El resultado a tomar en cuenta para el cálculo de los indicadores se obtuvo según la moda en la respuesta de los encuestados obteniendo los resultados del Cuadro 7.

Desarrollando la ecuación del ISEC, en cada uno de sus componentes, se tiene:

$$
I S E C=\frac{(C M O)+((D E+D T) / 2)+I R T T}{3}
$$

Con base en los resultados obtenidos en las encuestas y sustituyendo los valores en la ecuación, se tiene:

$$
I S E C=\frac{(3)+((1+0) / 2)+4}{3}
$$

Entonces, el indicador ecológico tiene un valor de 2.5, indicando que los pequeños productores son sostenibles en cuanto al criterio ecológico.

Cuadro 7

Resultados más altos de las escalas de sostenibilidad por indicador y subindicador de la Sostenibilidad Ecológica ${ }^{8}$

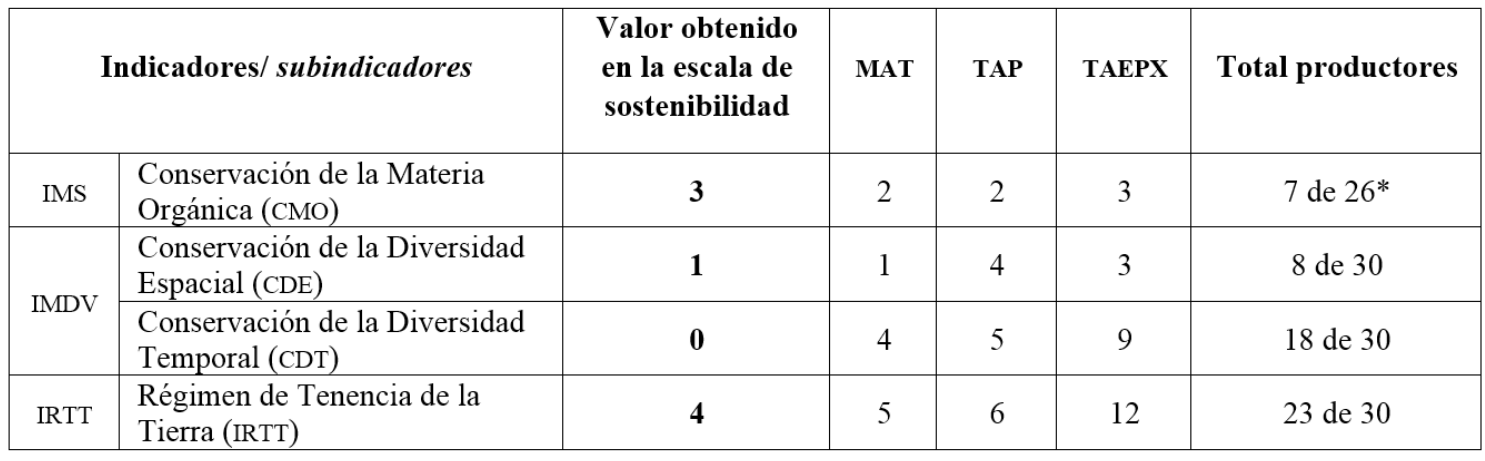

Fuente: Elaboración propia con base a las encuestas aplicadas de agosto 2014 a noviembre 2015.

* Para cuatro no aplica porque son comercializadores. 
El único valor que no resultó sostenible fue el de Conservación de la Diversidad Temporal, el cual implica que se lleve a cabo la rotación de cultivos, resultado que dio un valor de cero puesto que de los 30 encuestados, 18 no llevan a cabo esta actividad.

En cuanto a los resultados del Indicador de Sostenibilidad Socio-Cultural (Cuadro 8), se llevó a cabo la misma escala de medición que en los indicadores anteriores, sin embargo la ponderación cambia ya que se asignó el doble de peso al ISBN y al IASP por lo tanto, los resultados obtenidos, son:

Cuadro 8

Resultados más altos de las escalas de sostenibilidad por indicador y subindicador de la Sostenibilidad Socio-Cultural

\begin{tabular}{|l|l|c|c|c|c|c|}
\hline \multicolumn{2}{|c|}{ Indicadores/ subindicadores } & $\begin{array}{l}\text { Valor obtenido } \\
\text { en la escala de } \\
\text { sostenibilidad }\end{array}$ & MAT & TAP & TAEPX & $\begin{array}{c}\text { Total } \\
\text { productores }\end{array}$ \\
\hline \multirow{2}{*}{ INSB } & Acceso a la Educación (AE) & $\mathbf{3}$ & 4 & 6 & 8 & 18 de 30 \\
\cline { 2 - 6 } & Vivienda (V) & $\mathbf{1}$ & 2 & 4 & 4 & 10 de 30 \\
\hline \multirow{2}{*}{ IASP } & $\begin{array}{l}\text { Indicador de Aceptabilidad al } \\
\text { Sistema Productivo (IASP) }\end{array}$ & $\mathbf{3}$ & 4 & 6 & 3 & 13 de 30 \\
\hline IIS & Indicador de Integración Social (IIS) & $\mathbf{0}$ & 6 & 10 & 9 & 25 de 30 \\
\hline \multirow{2}{*}{ ICCE } & $\begin{array}{l}\text { Indicador de Conocimiento y } \\
\text { Conciencia Ecológica (ICCE) }\end{array}$ & $\mathbf{0}$ & 2 & 8 & 7 & 17 de 30 \\
\hline
\end{tabular}

Fuente: Elaboración propia con base a las encuestas aplicadas de agosto 2014 a noviembre 2015.

Con base en los resultados obtenidos en las encuestas y sustituyendo los valores en la ecuación, se tiene:

$$
I S C=\frac{2\left(\frac{1+2(3)}{3}\right)+2(3)+0+0}{6}
$$

El valor del Indicador Socio-Cultural es de 1.77 por lo tanto los productores no son sostenibles, puesto que la integración social es prácticamente nula al igual que la conciencia y el conocimiento ecológico medido a través de la asesoría técnica. Sin embargo estas cuestiones son fáciles de obtener puesto que son los mismos productores quienes pueden solicitar asesoría o apoyo a otros grupos que trabajen sobre las cuestiones orgánicas o en los mismos tianguis y mercados pertenecien-

8 Conservación de la Materia Orgánica, considera todas las actividades de mejora en la fertilidad del suelo donde el resultado mayor fue 0 , es decir que la mayoría de los productores no aplica estos métodos; la Conservación de la Diversidad Espacial, la diversidad de cultivos es de 2 a 4; Conservación de la Diversidad Temporal, considera que no hay rotación de cultivos y; el Régimen de Tenencia de la Tierra es en su mayoría propio.

9 El acceso a la educación indica el grado de escolaridad donde la moda es educación superior; respecto a la vivienda la sostenibilidad se da por el número de habitaciones por hogar (solo dormitorios); el Indicador de Aceptabilidad al Sistema Productivo los productores indicaron que la principal razón es comercial; Indicador de Integración Social es bajo puesto que los productores pertenecen a su tianguis o mercado y alguna otra organización por lo tanto se integran a 1 o 2 lugares solamente y; el Indicador de Conocimiento y Conciencia Ecológica donde se hace referencia a si los productores reciben asesoría técnica. 
tes a la REDAC y así, incrementar sus sostenibilidad socio-cultural.

El último de los indicadores a calcular fue el de sostenibilidad general, el cual es solamente la suma de los indicadores anteriores por lo tanto, sustituyendo los valores de cada uno:

$$
I S G=\frac{2.62+2.5+1.77}{3}
$$

Entonces, el valor del Indicador de Sostenibilidad General es de 2.62 lo cual indica sostenibilidad. Sin embargo, es necesario incrementar la sostenibilidad socio-cultural, puesto que el resultado obtenido mediante sus indicadores es de 1.77 es decir, al no alcanzar el valor mínimo de 2, implica que no sea sostenible. Esto se debe como se mencionó anteriormente, a la falta de conocimiento y conciencia ecológica, aunado a la poca integración social por parte de los productores.

\section{Conclusiones y recomendaciones.}

La agricultura orgánica ha crecido en diversos países y regiones del mundo, considerándose como una alternativa tanto para el cuidado del ambiente como para la inclusión de los pequeños productores en el mercado agrícola, sopesando así la exclusión que les ha dejado el modelo agrícola moderno. Este sistema de producción además, genera empleos, autosuficiencia alimentaria, bienestar económico, social y cultural a quienes lo llevan a cabo lo cual, se traduce en un mayor arraigo en la producción agrícola evitando el desplazamiento de mano de obra y el abandono de tierras de cultivo particulares.

Debido a que en algunos indicadores, no se alcanza la sostenibilidad, se proponen algunas acciones para alcanzarla, como por ejemplo para mejorar el nivel de sostenibilidad del indicador ecológico, se puede: brindar a los productores asesoría técnica y capacitación sobre las actividades a realizar para mantener la micro y meso fauna del suelo, ya sea mediante cursos o talleres impartidos por productores con más experiencia, estudiantes o incluso agregando como requisito en la CP métodos que incrementen la fertilidad del suelo, mediante prácticas orgánicas.

Respecto al indicador de Manejo del Suelo, este tiene un resultado que implica no sostenibilidad debido a que su subindicador tiene un valor de cero por lo tanto, debe llevarse a cabo una estrategia que ayude a concientizar a los productores sobre la importancia de realizar actividades como la diversificación, asociación y rotación de cultivos los cuales inclusive, son un requisito para llevar a cabo la producción orgánica. Entonces, para mejorar el valor de este indicador pueden efectuarse cursos y talleres de difusión y aprendizaje sobre cómo llevar a cabo estas prácticas.

En lo referente al Indicador de Sostenibilidad Socio-Cultural, los productores encuestados pertenecen o están relacionados solamente con una o dos organizaciones dentro de los que están sus propios tianguis o mercados por lo tanto, el subindicador de integración social no es sostenible ya que se requiere precisamente una mayor integración. Sin embargo, esta integración puede mejorar 
aumentando las relaciones entre productores lo cual, creará lazos de confianza donde incluso puede darse una relación laboral o de aprendizaje que sirva para mejorar el sistema productivo. Esto se puede llevar a cabo mediante la organización de ferias de productores, eventos tales como el que se lleva actualmente sobre el intercambio de semillas e incluso, reuniones informativas donde los miembros de diversos mercados interactúen entre sí. Para el caso del indicador de conocimiento y conciencia ecológica, el resultado da un valor de cero, lo cual indica la no sostenibilidad, ya que los productores no reciben o buscan asesoría la cual, les permite mejorar su producción. Por lo tanto, esta situación debe tratarse con urgencia puesto que los productores orgánicos son los principales actores que deben ser conscientes y tener conocimiento ecológico sobre como cultivar de manera amigable con el medio ambiente y sobre los efectos que pueden tener algunas prácticas en el mismo. Por consiguiente, se pueden implementar pláticas o talleres que muestren los efectos de las prácticas no ecológicas en el medio ambiente y ejemplos de proyectos orgánicos exitosos que puedan implementar y a su vez, los inspire y los lleve a mejorar su situación económica.

En cuanto a la sostenibilidad general, el resultado es sostenible pero mejorable, debido al indicador socio-cultural cuyo valor fue el único menor a 2. Sin embargo, la identificación de estos puntos débiles que son clave para la permanencia de la agricultura orgánica, permite implementar estrategias de mejora, con el objetivo de afianzar y fortalecer los pilares de la activad, lo que contribuirá a que los productores sean más conscientes sobre la agricultura orgánica y la prefieran ante la convencional.

Se debe aprovechar que los productores dedicados a la agricultura orgánica tienen un promedio de edad de 42 años y un nivel de escolaridad alto (puesto que $60 \%$ cuenta con educación superior) lo que hace viable la implementación de nuevas técnicas de producción, la capacitación, los trabajos de campo y la inclusión de métodos o estrategias que favorezcan a su producción.

También, es importante capacitar a los productores, ayudándoles a implementar técnicas para el control de costos e ingresos que les permita ser más consientes sobre los puntos que deben tener mayor enfoque y así, evitar pérdidas tanto en la producción como monetarias ya que, la percepción de los productores sobre la utilidad de la producción orgánica es mayor a la real.

Respecto a la perspectiva de los encuestados, estos mencionaron que para mejorar su situación se debe incurrir en un mayor cumplimiento de los lineamientos de producción orgánica; que no existan favoritismos dentro de los tianguis o mercados; que se dé una mayor difusión al consumo orgánico con el fin de que el consumidor conozca sobre la producción orgánica y consuma de forma responsable y solidaria. En lo referente a la certificación orgánica, mencionaron que se debe contar con un marco legal adecuado para reducir los costos de operación por concepto de certificación e inspección y a la vez, fortalecer los sistemas de certificación orgánica participativa, creando confianza para los consumidores y brindando a los productores más oportunidades de comercialización. 
Según lo que se observó al realizar el trabajo de campo, el hecho de integrarse a alguno de los tianguis y mercados orgánicos de la REDAC, brinda a los pequeños productores la oportunidad de ser sostenibles puesto que, tienen un espacio destinado a la venta de una producción específicamente orgánica que les brinda reconocimiento debido a que, para integrarse en estos mercados deben tener una certificación orgánica que los asigna dentro de una categoría de cumplimiento, permitiéndoles competir localmente en este ámbito. Por lo tanto tienen la posibilidad cubrir parte de su consumo con su propia producción, recibir un ingreso semanal a través de la comercialización de sus productos, lo cual a su vez mejora la satisfacción de sus necesidades básicas, conservando la salud de los suelos, manteniendo una producción diversificada (ya que deben incluir una buena oferta de productos en los tianguis y mercados), les da una mayor convicción sobre el sistema productivo y están más integrados tanto a otros productores como a sus propios consumidores por lo tanto mejoran en el tiempo su economía, son más ecológicos y mantienen los conocimientos obtenidos a través de las tradiciones y sus relaciones sociales, es decir son más sostenibles en estos criterios. 


\section{Bibliografía y referencias documentales}

Altieri, Miguel y Nicholls Clara. (2000). Teoría y práctica para una agricultura sustentable. Serie de Textos Básicos para la Formación Ambiental. PNUMA. Red de Formación Ambiental para América Latina y El Caribe.

Altieri, Miguel. (2008). "Agroecology: environmentally sound and socially just alternatives to the industrial farming model", Encyclopedia of Life Support Systems. Revisado el 14 de Agosto de 2014 en: http://agroeco.org/wp-content/uploads/2011/02/Altieri-Alternatives-to-industrialmodel-part-1. Pdf.

Altieri, Miguel. (2009). "La agricultura moderna: impactos ecológicos y la posibilidad de una verdadera agricultura sustentable". On-farm evaluation of the push-pill technology for the control of stemborers and Striga weed on maize in western Kenya. Field Crops Research 106 (3), pp.224-233. Revisado el 14 de abril de 2016 en: http://www.ayuntamientomotril.es/fileadmin/areas/medioambiente/ae/IOAgriculturaModerna.pdf

Arrow, Kenneth. Dasgupta, Partha. Goulder Lawrence. Mumford, K. y Oleson K. (2010). "Sustainability and the measurement of wealth" en Environment and development economics, 17 (03) Palo Alto CA, $45 \mathrm{p}$.

Boza Sofía. (2012). “Agricultura orgánica y desarrollo: un análisis comparativo entre países de América Latina", en Estudios regionales en economía, población y desarrollo, Cuadernos de trabajo UACJ, Noviembre/diciembre, No. 12, pp. 1-31.

CiaO e IICA. (2010). Sistemas de garantía para productos orgánicos en mercados locales y nacionales. Serie Publicación Miscelánea, San José, C.R, 53 p.

Codex Alimenatius. (2005). Alimentos producidos orgánicamente. Comisión del Codex Alimentarius Programa Conjunto FAO/OMS sobre Normas Alimentarias FAO, Roma, Italia pp. 1-65.

De la Cruz R, S., Gómez Laura. Gómez, Manuel Ángel. Y Schwentesius, Rita. (2012). "Regulación y normatividad de la agricultura orgánica en México y en el mundo", en Héctor Enrique Gaxiola Carrasco, Rita Elise Dora Schwentesius Rindermann, Manuel Ángel Gómez cruz, Belem Dolores Avendaño Ruiz y Juan de Dios Trujillo Félix (coords.), Competencia y dinámicas de ajuste en la horticultura, Universidad Autónoma de Sinaloa, 1 era ed. México, pp. 519-534.

Escalona, Miguel Ángel. (2009). Los tianguis y mercados locales de alimentos ecológicos en México: su papel en el consumo, la producción y la conservación de la biodiversidad y la cultura. Tesis doctoral. Universidad de Córdova, España, 420 p.

Fleurbaey, Marc. (2015). "On sustainability and social welfare” en: Journal of Environmental Economics and Management Vol. 71, pp. 34-53.

Flores, Patricia. (2015). "Organic Agriculture in Latin America and the Caribbean" en The world of organic agriculture, statistics and emerging trends 2015. Research Institute of Organic Agriculture (Fibl) e IFOAM pp. 223-236.

García, Rocio. (2015). "Tianguis alternativos locales en México, como puntos de encuentro micropolítico: en la búsqueda de posibilidades de vida en el presente", en Tesis doctoral. Benemérita Universidad Autónoma de Puebla, Facultad de Economía. Puebla, Pue, 261 p.

Gómez, Alberto. (2000). “Agricultura orgánica: una alternativa posible”, en Domínguez, A., y Prieto, G., R., (coords.), Perfil ambiental del Uruguay/ Documentos CEUTA/ nORDAN, Montevideo, Uruguay, pp. 14-30.

Gómez, Laura y Gómez, Manuel Ángel. (2004). “La agricultura orgánica en México: Un ejemplo de incor- 
poración y resistencia a la globalización”. Manuscrito no publicado, Oaxaca, México. Revisado 14 de agosto de 2014 en http://dlc.dlib.indiana.edu/dlc/handle/10535/1679

Gómez, Laura., Martin, Lauren., Gómez, Manuel Ángel., y Mutersbaugh, Tad. (2005). "Certified organic agriculture in Mexico: Market connections and certification practices in large and small producers", en Journal of Rural Studies Vol. 21, No.4, pp. 461-474.

Gómez, Manuel Ángel., Schwentesius Rita., Ortigoza, Javier., Gómez, Laura., May, Vladimir., López, Ulises., Arreola, Jorge., y Noriega, Gerardo. (2010). Agricultura, Apicultura y Ganadería Orgánicas de México-2009: estado actual, retos tendencias. México, Universidad Autónoma Chapingo (UACh), Consejo Nacional de Ciencia y Tecnología.

Gómez. P. A.2000. Agricultura orgánica: una alternativa posible. Programa de agroecología, documentos Ceuta. Domínguez, A., y Prieto, G., R., (coordinadores). Publicado en "Perfil ambiental del Uruguay" NORDAN. Montevideo, Uruguay, pp. 14-30.

González, Humberto. (2010). "Certificación de tercera parte”, en IICA, \& CIAO (coords.), Sistemas de garantía para productos orgánicos en mercados locales y nacionales. Serie Publicación Miscelánea A2/JM (IICA), (96-002). Kingston, Jamaica, pp. 31-41.

IFOAM, PREÁmbUlo III. 2013. "Sistemas Participativos de Garantía: Estudios de caso en América Latina", en International Federation of Organic Agriculture Movements (IFOAM), Alemania, 48 p.

IfoAm. (2008). Definition of organic agricultura en International Federation of Organic Agriculture Movements: http://infohub.ifoam.bio/sites/default/files/page/files/doa_spanish.pdf

Jarquín, Ramón., Schwentesius, Rita., Escalona, Miguel Ángel., Ramírez, Hugo., y Domínguez, Nancy. (2013). Guía para la comprensión de lineamientos técnicos de operación orgánica. 1era ed. Universidad Autónoma San Luis Potosí, Universidad Veracruzana, Red Mexicana de Tianguis y Mercados Orgánicos. México, 86 p.

Jovchelevich, Pedro. (2013). "Sistema participativo de Garantía ABD- Brasil", en Sistemas Participativos de Garantía: Estudios de caso en América Latina. International Federation of Organic Agriculture Movements (IFOAM), Alemania, $8 \mathrm{p}$.

Källander, I., y Rundgren, G. 2009. “Construyendo sectores orgánicos sustentables” en International Federation of Organic Agriculture Movements (IFOAM), Alemania, 89 p.

Kilcher, Likas., Willer, Helga., Huber, Beate., Frieden, Claudia,, Schmutz, Res., Schmid, Otto. (2011). “The Organic Market in Europe: Overview and market Access Information for Producers and International Trade of Companies. Fourteen Country Examples in the European Free Trade Association and the European Union, with a Special Focus on Switzerland". 3era ed. SIPPO and FiBL, 268 p.

Kirchner, Cornelia. (2015). "Overview of participatory guarantee systems in 2014", en The world of organic agriculture, statistics and emerging trends 2015. Research Institute of Organic Agriculture (Fibl) e IFOAM, pp. 134-137.

Lernoud, Julia y Willer Helga. (2015). "Organic Agriculture Worldwide: Current statistics", en The world of organic agriculture, statistics and emerging trends 2015. Research Institute of Organic Agriculture (Fibl) e IFOAM, pp. 31-116.

Martinet, Vincent. (2009). “A characterization of sustainability with indicators”, en: Journal of Environmental Economics and Management, Vol.61, No. 2, pp.183-197.

May, Christopher. (2008). "Lineamientos para SPG. Cómo pueden desarrollarse y funcionar los Sistemas Participativos de Garantía", en International Federation of Organic Movements (IFOAM). Bonn, Alemania, $26 \mathrm{p}$. 
Méndez, Ana y Sáenz, Alba. (2007). "Desarrollo sostenible y economía: una mirada hacia el futuro”, en Macroeconomía aplicada, Máster EID, pp.3-17.

Nelson, Erin., Schwentesius, Rita., Gómez, Laura y Gómez, Manuel Ángel. (2007). "Experiencias de la Red Mexicana de Tianguis y Mercados Orgánicos: el nacimiento de un movimiento orgánico local en México", en http://www.tianguisorganicos.org.mx/wp-content/uploads/2012/07/ExperienciasREDAC.pdf

REDAC, 2013. Antecedentes. Revisado en mayo de 2013, http://tianguisorganicos.org.mx/antecedentes/

Rendón, Roberto. (2004). Evaluación comparativa de sustentabilidad en sistemas agrícolas convencionales, mixtos y orgánicos de México. Tesis doctoral. Universidad Autónoma Chapingo, Centro de Investigaciones Económicas, Sociales y Tecnológicas de la Agroindustria y la Agricultura Mundial (CIESTAAM), Chapingo, Estado de México, 230 p.

Roy, Anhijit y Goll, Irene. (2014). "Predictors of various facets of sustainability of nations: the role of cultural and economic factors", en International Business Review, Vol. 23, No. 5, pp.849-861.

Sáenz, Ana maría. (2009). La agricultura y su evolución a la agroecología. Obra propia, Editorial. España, pp. 3-6.

Sarandon, Santiago y Dellepiane, Andrea. (2008) "Evaluación de la sustentabilidad en fincas orgánicas, en la zona hortícola de La Plata, Argentina", en Revista brasileira de agroecologia Vol.3, no. 3 pp. 68-78.

Sarandón, Santiago. (2002). "El desarrollo y uso de indicadores para evaluar la sustentabilidad de los agroecosistemas”, en Agroecología: El camino para una agricultura sustentable, Vol. 20 pp. 393-414.

Sarandón, Santiago., Zuluaga, María Soledad., Cieza, Ramón., Janjetic, Leonardo., y Negrete, Eliana. (2008). "Evaluación de la sustentabilidad de sistemas agrícolas de fincas en Misiones, Argentina, mediante el uso de indicadores", en Agroecología, vol. 1, pp. 19-28.

Schwentesius, Rita. (2015). "Organic Agriculture in Latin America and the Caribbean. (2015)”, en Helga Willer y Julia Lernoud (cords.), the world of organic agriculture: statistics \& emerging trends 2015. FiBL- IFOAM Report. Research Institute of Organic Agriculture (FiBL), Frick, and IFOAM-Organics International, Bonn, pp. 12-281.

Schwentesius, Rita., Gómez, Manuel Ángel y Nelson, Erin. (2013). "La Red Mexicana de Tianguis y Mercados Orgánicos- México: Renovando sistemas de abasto de bienes de primera necesidad para pequeños productores y muchos consumidores", en Sistemas Participativos de Garantía: Estudios de caso en América Latina. International Federation of Organic Agriculture Movements (IFOAM), Alemania, pp. 21-34.

SOCLA y TWIN. (2015). Agroecology: Key concepts, principles and practices. Jutaprint, Malaysia, 52 p.

Solow, Robert. (1991) "Sustainability: an economist's perspective", enn la Lectura 18 de J. Seward Johnson, para el Centro de la Política Marítima, Woods Hole Oceanographic Institution en Woods Hole, Massachusetts.

Soto, Gabriela. (2003). Memoria del taller: "Agricultura orgánica; una herramienta para el desarrollo rural sostenible y la reducción de la pobreza", en Gabriela Soto, coordinadora del taller Turrialba, Texto: Expositores y organizadores del taller. Elaboración: FIDA, RUTA, CAITE, FAO Costa Rica, p.109.

Van Elzakker B. y Eyhorn F. (2010). "La guía de negocios orgánica: Desarrollar cadenas de valor sostenibles con pequeños agricultores", en International Federation of Organic Agriculture Movements (IFOAM), Bonn, Alemania, 164 p.

Willer, Helga y Lernoud, Julia. (2015). "The world of organic agriculture 2015: summary", en The world of 
organic agriculture, statistics and emerging trends 2015. Research Institute of Organic Agriculture (Fibl) e IFOAM pp. 24-30.

World Comission on Environment and Development. (1987). "Report of the World Commission on Environment and Development: Our Common Future. Transmitted to the General Assembly as an Annex to document A/42/427 - Development and International Co-operation: Environment", en http://www. un-documents.net/wced-ocf.htm

Zayas, Rosa Armida., Zayas, Imelda y Castro, Jorge Arturo. (2012). “Agricultura orgánica: alternativa del futuro para el desarrollo sustentable en Héctor Enrique Gaxiola Carrasco, Rita Elise Dora Schwentesius Rindermann, Manuel Ángel Gómez cruz, Belem Dolores Avendaño Ruiz y Juan de Dios Trujillo Félix (coords.), Competencia y dinámicas de ajuste en la horticultura, Universidad Autónoma de Sinaloa, 1 era ed. México, pp. 435-448. 


\section{Números anteriores:}

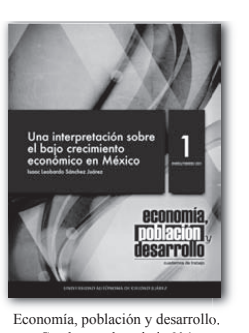

Economía, población y desarrollo
Cuadernos de trabajo №1

Enero-Febrero 2011

Una interpretación sobre el bajo
crecimiento económico en Méxice

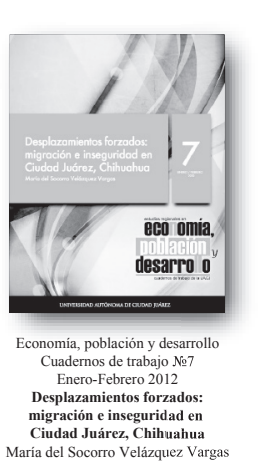

Ciudad Juárez, Chihuahua
Maria del Socorro Veläzquez Vargas

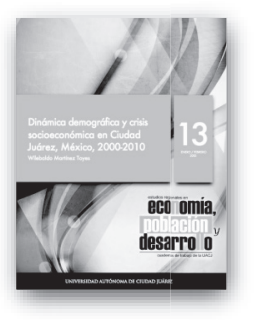

Economía, población y desarrollo
Cuarednos de trabajo № 13 Enero - Febrero 2013

fica y crisis

México, 2000-2010
Wilebaldo Martinez Toyes
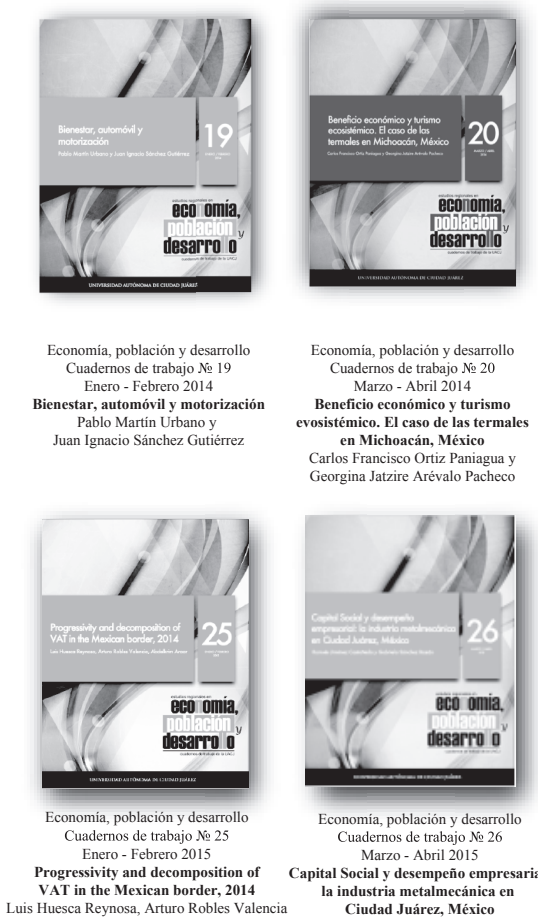

Economía, población y desarrollo
Cuadernos de trabajo № 14 Carlos Francisco Ortizi Paniagua y
Georgina Jatzire Arévalo Pacheco
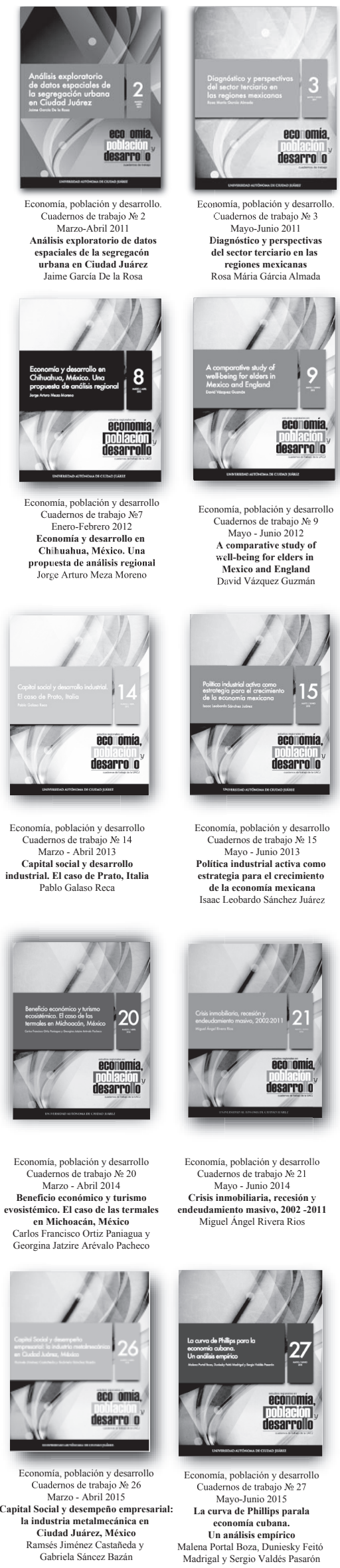

Capital social y desarrollo

strial. El caso de Prato, It
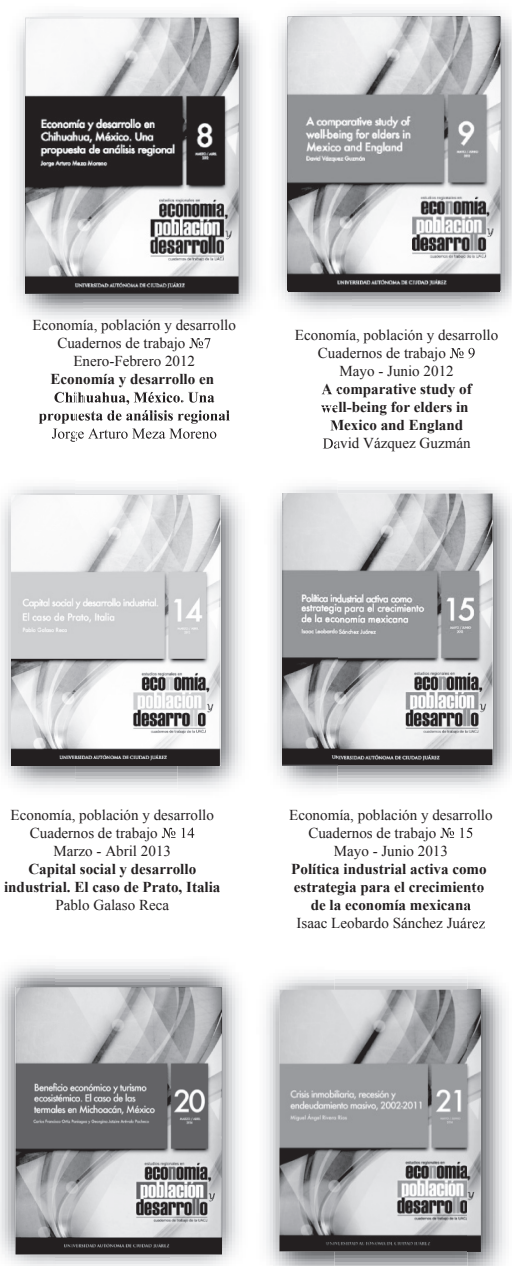

Economía, población y desarrollo
Cuadernos de trabajo № 15

Política industrial activa como de la economia mexicana
Isaac Leobardo Sánchez Juárez

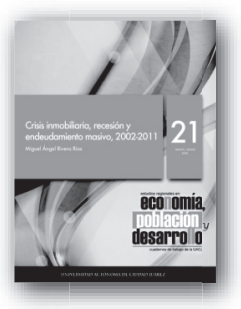

Economía, población y desarrollo
Cuadernos de trabajo № 21 Mayo - Junio 2014 Crisis inmobiliaria, recesión y
endeudamiento masivo, 2002 -2011 Miguel Ángel Rivera Rios

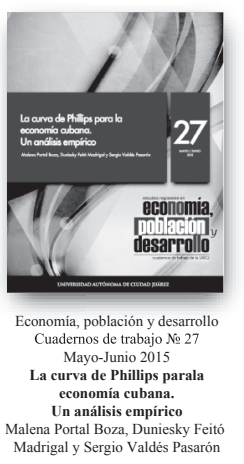

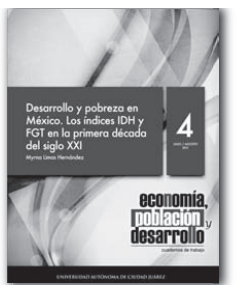
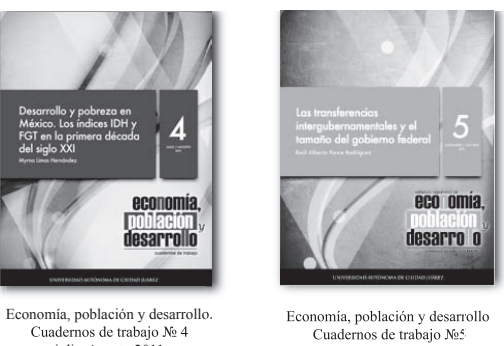

julio-Agosto 2011

Dasarrollo y pobreza en México.
Los indices IDH y FGT en la primera década del siglo XXI

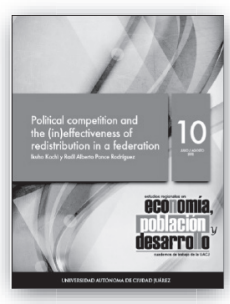

Economía, población y desarrollo

Cuadernos de trabajo № 10

Political competition and the

(in)effectiveness of
distribution in a federatio

Ikuho Kochi y Raúl Alberto Ponce
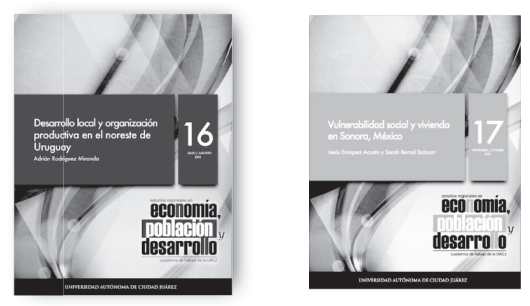

Economía, población y desarrollo
Cuadernos de trabajo № 16

surrollo - local y or or

Desarrollo local y organización
productiva en el noroeste de Urugua

Adrián Rodriguez Miranda
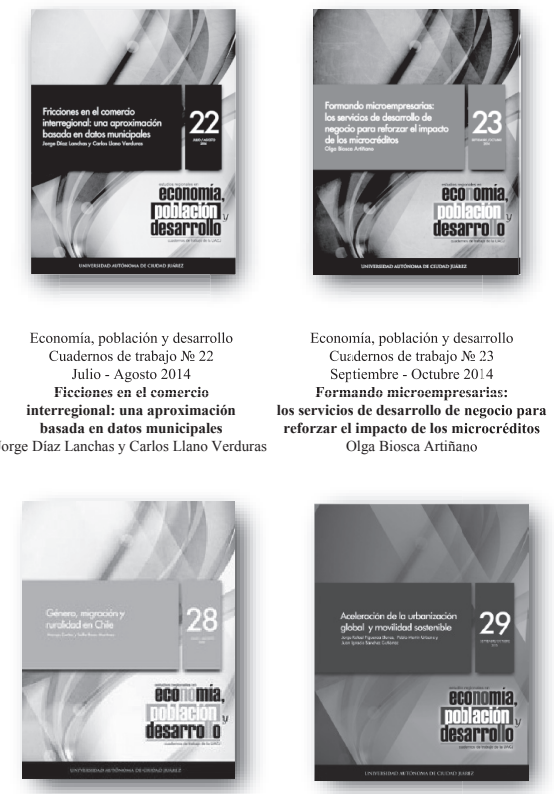

Cuadernos de trabajo № 28
Julio - Agosto 2015

Género, migración y ruralidad

en Chile.
Maruja Cortés y Sofía Boz

Economia, población y desarrollo
Cuadernos de trabajo №5

Septiembre-Octubre 205

intergubernamentales $y$ el

tamaño del gobierno federal
Raúl Alberto Ponce Rodriguez

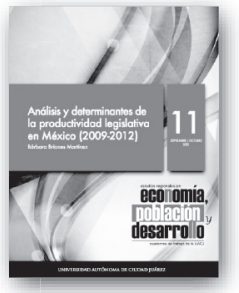

Economía, población y desarrollo

Cuadernos de trabajo № 11

Análisis y determinantes de en México (2009-2012)

Economía, población y desarrollo
Cuadernos de trabajo № 17 Vulnerabilidad social y viviend en Sonora, México
esús Enríquez Acosta y Jesús Enríquez Acosta y
Sarah Bernal Salazar
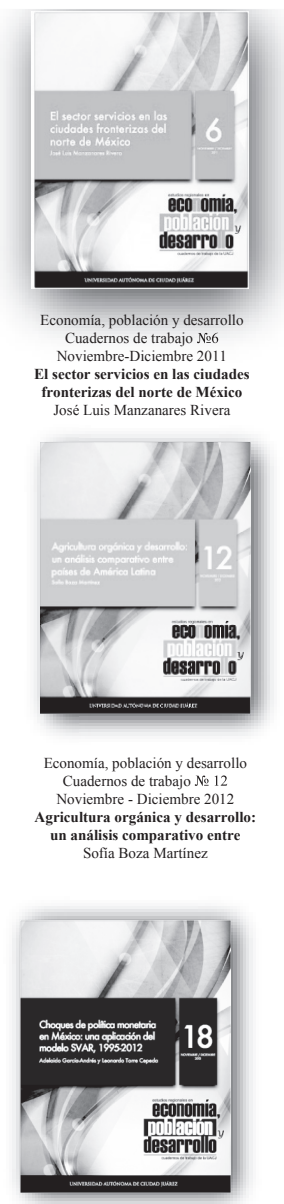

Cuaderabsación y desarrollo Cuadernos de trabajo № 18

Choques de politica monetaria en México: una aplicación del
modelo SVAR, 1995-2012
Adelaido García-Andés y Leonardo Torre Ce

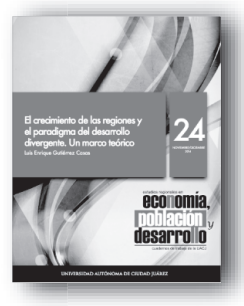

Conomia, población y desarrollo Noviembre - Diciembre 2014 El crecimiento de las regiones $y$ el paradigma del desarrollo
divergente. Un marco teórico Luis Enrique Gutiérrez Casas

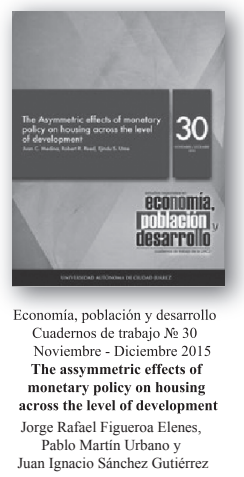


Números anteriores:

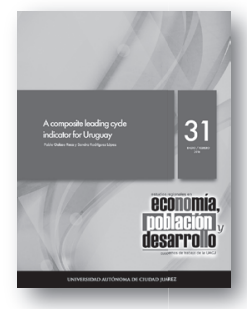

Economia, población y desarrollo Cuadernos de trabajo № 31 A composite leading cycle Pablo Galaso Reca y Sandra Rodriguez López
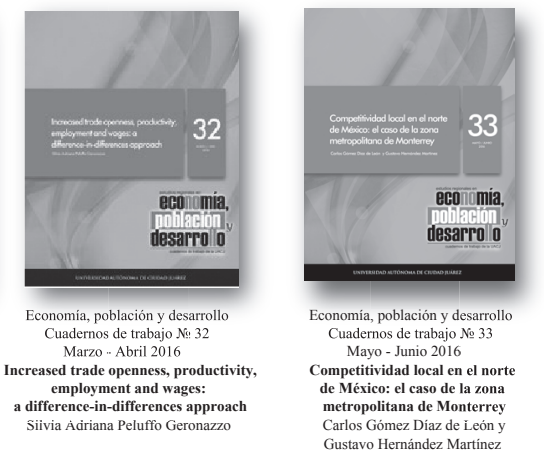

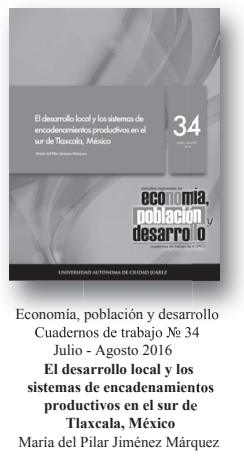

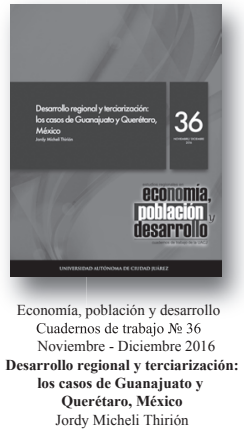




\section{$\rightarrow$ Normas Editoriales}

\section{Para el documento general:}

Tipo de letra: Times New Roman.

Tamaño: 11 puntos.

Interlineado: 1.5 espacios.

Títulos y subtítulos:

El texto principal en 11 puntos. Títulos 12 puntos (en resaltado). Subtítulos 11 puntos. Cada título y subtítulo deberá numerarse bajo el siguiente orden: $1,1.1,2,2.1,2.2 \ldots$

La extensión máxima de los cuadernos de trabajo será de 40 cuartillas.

La primera vez que se emplee una sigla en el texto se especificará primero su equivalencia completa y después la sigla.

\section{Hoja de presentación:}

Título:

14 puntos, centrado, resaltado.

Nombre de autor(es):

12 puntos

Resumen y abstract:

Debe incluir resumen en español y abstract (diez puntos), no mayor a 250 palabras

Palabras clave:

Incluir entre tres y cinco palabras clave, en español e inglés

Referencia del autor o autores:

Institución de adscripción, grado académico y líneas-grupos de investigación que desarrolla y a los que pertenece.

\section{Sistema de referencia de citas:}

Harvard-APA

Las citas bibliográficas en el texto deberán incluir entre paréntesis sólo el apellido del autor, la fecha de publicación y el número de página; por ejemplo: (Quilodrán, 2001: 33).

\section{Notación en sección de bibliografía y fuentes de información:}

Se deberá incluir al final del texto. Toda referencia deberá estar mencionada en el texto o notas de pie de página.

Cada referencia iniciará con el primer apellido o los apellidos, luego el nombre del autor, y después, entre paréntesis, el año de publicación seguido de un punto. Ejemplos:

Se deberá incluir al final del texto. Toda referencia deberá estar mencionada en el texto o notas de pie de página.

Cada referencia iniciará con el primer apellido o los apellidos, luego el nombre del autor, y después, entre paréntesis, el año de publicación seguido de un punto. Ejemplos:

Artículo:

Ros, Jaime (2008). "La desaceleración del crecimiento económico en México desde 1982”, en Trimestre Económico, vol. 75, núm. 299, pp. 537-560.

Libro:

Villarreal, René (2005). Industrialización, competitividad y desequilibrio externo en México. 
Un enfoque macroindustrial y financiero (1929-2010), México, Fondo de Cultura Económica. Capítulo de libro:

Castillo, Manuel Ángel (2003). "La política de inmigración en México: un breve recuento", en Manuel Ángel Castillo, Alfredo Lattes y Jorge Santibáñez (coords.), Migración y fronteras, Tijuana, El Colegio de la Frontera Norte / Asociación Latinoamericana de Sociología / El Colegio de México, pp. 425-451.

\section{Notas de pie de página:}

Se utilizarán para hacer indicaciones complementarias, aclaraciones o ampliación de una explicación. La notas de pie de página en Times New Roman, 10 puntos.

\section{Tipología de imágenes dentro del texto:}

Cuadro

Gráfica

Diagrama

Mapa

Figura

Todas las imágenes deben ser numeradas y mencionadas dentro del texto. A toda imagen debe incluirse la fuente.

Las indicaciones de la imagen: tipo y número de imagen, título de imagen y fuente se escriben en 10 puntos. En el texto poner como imagen los mapas, figuras, gráficas y diagramas -con el ánimo de no perder el formato realizado por el autor.

\section{Ecuaciones y fórmulas:}

Si se utilizan ecuaciones o fórmulas deberá utilizarse el editor de ecuaciones de Word y numerarse.

\section{Envío de trabajos}

Los trabajos deben ser enviados a la dirección de correo: lgtz@uacj.mx. Con el Dr. Luis Enrique Gutierrez Casas, editor de esta publicación.

La aceptación de cada colaboración dependerá de la evaluación de dos dictaminadores especialistas en la materia que se conservarán en el anonimato, al igual que el autor (autores) para efectos de la misma. 


\section{$\rightarrow$ Editorial Guidelines}

\section{For General Document:}

Font type: Times New Roman.

Size: font size 11 .

Paragraph: 1.5 line spacing.

Titles and subtitles: Main text font size 11. Titles font size 12 (Bold). Subtitles font size 11.

Each title and subtitle should be numbered in the following order: 1, 1.1, 2, 2.1, 2.2...

The maximum length of the workbooks will be 40 pages.

The first time an abbreviation is used in the text will be specified first complete equivalence and then stands.

\section{Front cover:}

Title:

Font size 14, centered, Bold.

Author name(s):

Font size 12.

Abstract:

It should include abstract in Spanish and abstract (font size 10), no more than 250 words.

Keywords:

Include three to five keywords, in Spanish and English.

Reference of author:

Institution of affiliation, academic degree and line-developed by research groups and belonging.

\section{Bibliographical appointment system:}

Harvard-APA

Citations in the text should include between parentheses only the author's name, publication date and page number, for example:

(Quilodrán, 2001: 33).

\section{Notation about Bibliography section and Information fonts:}

Should be included at the end of the text. All references must be mentioned in the text or footnotes page.

Each reference starts with the first name or last name, then the name of the author, and then, in parentheses, the year of publication followed by a period. Examples:

Article:

Ros, Jaime (2008). “La desaceleración del crecimiento económico en México desde 1982”, en Trimestre Económico, vol. 75, núm. 299, pp. 537-560.

Book:

Villarreal, René (2005). Industrialización, competitividad y desequilibrio externo en México. Un enfoque macroindustrial y financiero (1929-2010), México, Fondo de Cultura Económica.

Book chapter:

Castillo, Manuel Ángel (2003). "La política de inmigración en México: un breve recuento”, en Manuel Ángel Castillo, Alfredo Lattes y Jorge Santibáñez (coords.), Migración y fronteras, Tijuana, E1 Colegio de la Frontera Norte / Asociación Latinoamericana de Sociología / El Colegio de México, pp. 425-451. 


\section{Footnotes:}

Must be used to make additional indications, clarification or expansion of an explanation. The footnotes must be in Times New Roman, font size 10.

\section{Image typology inside text:}

Picture

Graph

Diagram

Map

Figure

All images must be numbered and mentioned in the text, should include the source image. The indications of the image: type and number of image, image title and source are written in 10 font size. In the text set as image maps, figures, graphs and charts-with the intention of not losing the formatting by the author.

\section{Equations and Formulae:}

When using equations or formulas should be used in Microsoft Word equation editor and numbered.

\section{Paper sending}

Entries must be sent to the email address: lgtz@uacj.mx. With Dr. Luis Enrique Gutiérrez Casas, editor of this publication.

Acceptance of each collaboration will depend on the evaluation of two examiners skilled in the art to be kept anonymous, like the author(s) for the same purposes. 


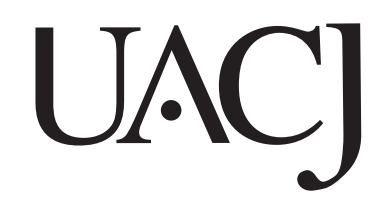

Esta obra se terminó de imprimir en diciembre de 2016

Cd. Juárez, Chihuahua, México.

Tiraje: 120 ejemplares 
Cuadernos de Trabajo de la Universidad Autónoma de Ciudad Juárez, número 37, enero-febrero de 2017

\section{Director y editor}

Dr. Luis Enrique Gutiérrez Casas

\section{Comité editorial}

Sección internacional

Dra. Sofía Boza Martínez (Universidad de Chile, Chile)

Dra. Olga Biosca Artiñano (Glasgow Caledonian University, Reino Unido)

Dra. Ángeles Sánchez Díez (Universidad Autónoma de Madrid, España)

Dr. Thomas Fullerton Mankin (University of Texas at El Paso, Estados Unidos)

Dr. Adrián Rodríguez Miranda (Universidad de la República, Uruguay)

\section{Sección local}

(Universidad Autónoma de Ciudad Juárez)

Dra. Myrna Limas Hernández

Dra. Ikuho Kochi

Dr. Raúl Alberto Ponce Rodríguez

Dr. Isaac Leobardo Sánchez Juárez

Dr. Héctor Alonso Barajas Bustillos

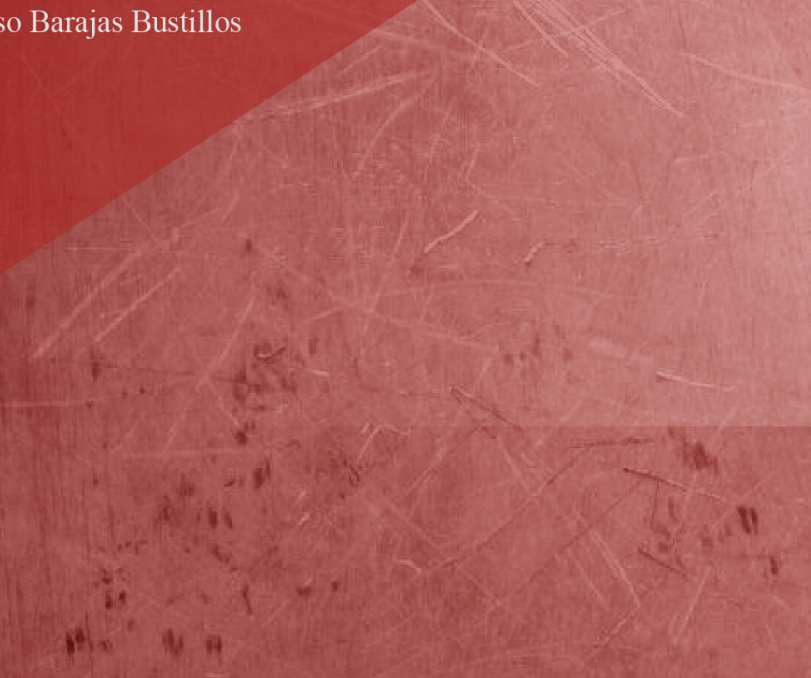

Universidad Autónoma de Ciudad Juárez

Instituto de Ciencias Sociales y Administración

Cuadernos de Estudios Regionales en

Economía, Población y Desarrollo ISSN 2007-3739

Cuerpo Académico de Estudios Regionales en Economía, Población y Desarrollo

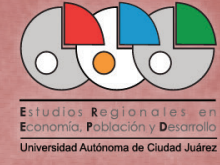

www.estudiosregionales.mx

UAC]

CUERPOS

ACADÉMICOS

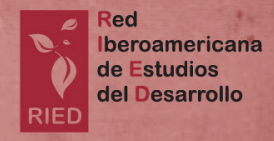

Publicación afiliada a la Red Iberoamericana de it. Estudios del Desarrollo

(c) Universidad Autónoma de Ciudad Juárez Avenida Plutarco Elías Calles \#1210, Fovissste Chamizal Ciudad Juárez, Chih., México. www.uacj.mx 